\title{
Bizans Pembesi: Alexis Gritchenko'nun Konstantinopolis Anlatısı
}

\section{Byzantine Pink: Alexis Gritchenko's Narrative of Constantinople}

\author{
Emir Alışık ${ }^{1}$
}

'(Doktora Öğrencisi), İstanbul Üniversitesi, Edebiyat Fakültesi, Sanat Tarihi Bölümü, İstanbul, Türkiye

ORCID: E.A. 0000-0003-0441-5812

Sorumlu yazar/Corresponding author: Emir Alısıı,

Istanbul Üniversitesi, Edebiyat Fakültesi, Sanat Tarihi Bölümü, Istanbul, Türkiye

E-posta: emiralisik@gmail.com

Başvuru/Submitted: 07.02.2021

Revizyon Talebi/Revision Requested: 26.04.2021

Son Revizyon/Last Revision Received: 05.05.2021

Kabul/Accepted: 08.06.2020

Online Yayın/Published Online: 30.06 .2021

Atuf/Citation: Alisik, Emir, "Bizans Pembesi: Alexis Gritchenko'nun Konstantinopolis Anlatısı". Sanat Tarihi Yıllığı - Journal of Art History 30 (2021), 1-27. https://doi.org/10.26650/sty.2021.876268

\section{öz}

1919 Kasım'ı ile 1921 Nisan'ı arasını İtilaf kuvvetlerinin işgali altındaki İstanbul'da geçiren Ukraynalı ressam Alexis Gritchenko (Oleksa Hryshchenko), 1923'te Paris'te Constantinople Bleu et Rose (Konstantinopolis Mavi ve Pembe) sergisini açtı ve 1930 'da halen yaşadığı Paris'te İstanbul'da tuttuğunu söylediği günlüğünü yayımladı. Günlük'te Bizans Konstantinopolis'ine, onun tarihine, kültürüne, sanatına, mimarisine dair pek çok bilgi verir. Gritchenko'nun aktarımları hem güncel tarihyazımına hem de kişisel gözlemlerine dayanır ve tüm bunları duyusal bir deneyim olarak sunar. Gözlemleriyle beslediği tarih bilgisi, Günlük'te antik, Bizans ve Osmanlı́dan parçalar taşıyan eklektik ve tarihdışı bir Konstantinopolis olarak karşımıza çıkar. Gritchenko, Bizantinizm olarak değerlendirilebilecek eserler üreten modernist bir ressamdır, bu yönüyle çağının bir temsilcisidir; Vladimir Tatlin, Vasily Kandinsky gibi Gritchenko da Bizans sanatı üzerine düşünmüştür. Gritchenko'nun sözlü betimindeki duyusallık ve eklektik tarih algısı İstanbul'da ürettiği resimlerde de gözlenebilir. Özellikle şehrin Bizans surları ve Ayasofya'yı tasvir ettiği eserlerde Bizans ve Osmanlı ögeleri iç içe geçer. Gritchenko'nun Günlük'te kurguladığı Tarihi Yarımada, mekânları, yapıları, insanları ve onların gündelik hayatlarıyla tarihin akışının dışında kalmış, ancak tüm parçaları birbiriyle uyum içinde kurgulanmış fantastik atmosferiyle bir hierotopos'tur. Bu yazıda Günlük'te Bizans tarihi, yapıları ve kültürüne yapılan atıflar saptanmış ve bunlar hem çağdaş hem de Gritchenko'nun erişimi olabilecek yazın çerçevesinde değerlendirilmiştir. Böylece Gritchenko'nun, okuma ve gözlemlerine dayalı Konstantinopolis'ini nasıl kurguladığı gösterilmiştir.

Anahtar kelimeler: Alexis Gritchenko, Konstantinopolis, Bizantinizm, Hierotopos, Tarihyazımı

\section{ABSTRACT}

Ukrainian artist Alexis Gritchenko (Oleksa Hryshchenko), who lived in Istanbul between November 1919 and April 1921 during the occupation of the Allied forces, opened the Constantinople Bleu et Rose exhibition in Paris in 1923, where he displayed his works on Constantinople. In 1930, while living in Paris, he published a chronicle of his life in Istanbul (Deux ans à Constantinople). It depicted the Byzantine history, culture, art, and architecture in Constantinople. While his knowledge benefited from both the contemporary historiography and his scrutiny, he presents them as sensory experiences. What emerged 
was an ahistorical Constantinople, an amalgamation of eclectic features from the Ancient, Byzantine, and Ottoman periods of the capital. Gritchenko was a modernist artist who produced Byzantinism, much like his cohort, including Vladimir Tatlin or Vasily Kandinsky. His art reflected sensuous oral descriptions and eclectic representations of history, reproducing Byzantinism. The Historical Peninsula in Gritchenko's journal is a hierotopos, a carefully rendered, fantastic atmosphere with ahistoric yet harmoniously functioning spaces, buildings, people, and daily life. This article evaluates and assesses the journal's references to Byzantine history, monuments, and culture in the context of both the contemporary literature on Byzantine history and the literature that Gritchenko may have accessed. Thus, we reveal how Gritchenko constructed a Constantinople based on his readings and observations.

Keywords: Alexis Gritchenko, Constantinople, Byzantinism, Hierotopos, Historiography

\section{EXTENDED ABSTRACT}

Ukrainian artist Alexis Gritchenko (Oleksa Hryshchenko), who lived in Istanbul between November 1919 and April 1921 during the occupation of the Allied forces, opened the Constantinople Bleu et Rose exhibition in Paris in 1923, where he displayed his works on Constantinople. In 1930, while living in Paris, Gritchenko has published Deux ans à Constantinople (Two Years in Istanbul), a chronicle of his life in Istanbul. Gritchenko had previously published works comparing Byzantine, Russian, and Italian Renaissance art. He wrote about the interconnectedness of all three, asserting that Russian art is rooted in Byzantine culture. His Journal is replete with information on Byzantine Constantinople, including its history, culture, art, architecture, and Ottoman art and architecture. It also includes his challenges against deprivation. The Byzantine materials that Gritchenko covered are examples of his historiographical knowledge, historical understanding, and experience of Constantinople. The Byzantine monuments, art, and historical events discussed here are Hagia Sophia, Khora Monastery, city walls (specifically Land Walls), Church of Hagia Anastasia, Monastery of Sts. Peter and Paul, St. Thekla, Hagia Theodosia, Christ Euergetis, Hippodrome, Nika Riot, the Fourth Crusade, the Fall of Constantinople, biblical figures, such as Theotokos, St. Matthew, St. George, Johannes Chrysostomos, Paulos Silentarios, icons and iconography, rituals, and music. While his knowledge benefited from contemporary historiography and his scrutiny, he presented them as sensory experiences. What emerged was an ahistorical Constantinople, an amalgamation of eclectic features from the Ancient, Byzantine, and Ottoman periods of the capital. In his writing, the Ottoman and Byzantine heritage and urbanites mingle in such a peculiar way, engulfing the reader in an impossible time-space continuum. Gritchenko benefited greatly from primary sources and contemporary historiography. His references trace back to Russian Primary Chronicle, Voskresenskaya Chronicle, Geoffrey Villehardouin's chronicle, Doukas' history, Paulos Silentarios' ekphrasis on Hagia Sophia, most contemporary works of Charles Diehl, Theophile Gautier, P.A. Dethier, Fyodor Uspensky. The sensuosity of his oral description and eclectic historical representations are remarkable in his art, too. In this respect, Gritchenko was a modern artist who produced Byzantinism, much like others in his era. Fellow painter, Vladimir Tatlin, had a similar understanding of art in such pieces as 
Composition-Analysis. In 1910, Alexander Benois called the Russian avant-garde movement the "Byzantinism of our age." Vasily Kandinsky acknowledges the impact of Byzantine art in modernist art. His Byzantinism was not limited to style but extended to the subject matter of his paintings. In Meşher's 2020 exhibition Alexis Gritchenko: The Constantinople Years, which formed the basis of this article, twelve paintings were exhibited under the Hagia Sophia and Byzantine Monuments title, but so many more featured Byzantine topics. Among them, there was even a study of a mosaic scene from Khora Monastery. In Istanbul, Gritchenko sold sixty-six paintings to Thomas Whittemore, who would later restore Khora Monastery and Hagia Sophia, which are now lost. The majority of them probably featured Byzantine elements, considering Whittemore's passion for Byzantine studies. The Historical Peninsula depicted in Gritchenko's journal and art is a hierotopos, a fantastic atmosphere, oral and visual, of ahistoric yet harmoniously functioning spaces, buildings, people, and daily life. 


\section{Giriş}

Sovyetler Birliği’ndeki Müzeler ve Sanat Eserlerinin Korunması Komitesi yönetim kurulundaki pozisyonunu ve Özgür Devlet Sanat Atölyeleri’ndeki görevini terk edip 1919 Kasım'ı ile 1921 Nisan'ı arasını İtilaf Devletleri'nin işgali altındaki İstanbul〉da geçiren ressam Alexis Gritchenko (Oleksa Hryshchenko), Fransa'ya yerleşmesinin ardından 1930 yılında, İstanbul'dayken tuttuğunu söylediği hatıratı Deux ans à Constantinople'u (İstanbul'da İki Y1l 1919-1921: Bir Ressamın Günlüğ̈̈) ${ }^{1}$ yayımlad1. ${ }^{2}$ Eserinde, Bizans İmparatorluğu'nun kültürel mirası büyük yer tutar ve ressamın, çoğunluğu maddi zorlukla geçen İstanbul günlerinde bu kültürel varlıklarla hem onları ziyaret ederek hem de zihinsel olarak girdiği etkileşim detaylıca takip edilebilmektedir. Günlük, günlere ve günlerin altında da ziyaret edilen yapı veya mekanlara ayrılarak kurgulandığı için ressamın hangi Bizans yapılarını ne sıklıkla ziyaret ettiği ölçülebilir durumdadır. Bunun yanında, bu ziyaretlere geniş anlatılar eşlik ettiği için Gritchenko'nun hangi kaynaklara ve gözlemlere dayanarak Bizans'a dair olandan bahsettiğinin izini sürmek kısmen mümkündür, bu da iltica etmiş modernist bir Ukraynalı ressamın entelektüel dünyasının - Bizans tarihi literatürü bağlamıyla sınırlı olsa da — barındırdıklarını görünür kılar. Bu yazıda, ressamın Bizans'a olan yoğun ilgisinin sebepleri ve Bizans'a dair bilgilerinin ve aktardıklarının olası kaynaklarıyla, tarihyazımı konusundaki fikirlerini irdeleyip, Rus tarihi ve erken yirminci yüzyıl modernist sanat bağlamından kaynaklandığını düşündüğüm Bizans’a olan ilgisini Günlük'te aktarırken başvurduğu akademik bir disiplinle romantik bir seyyah arasında dalgalanan üslubunu göstereceğim.

Günlüğünden yola çıkarak Gritchenko'nun Bizans'a olan ilgisini iki ana başlıkta toplamak mümkün. Bunların birincisi onuncu yüzyıl Rus devletinde Ortodoksluğun kabulüne yaptığı atıflar ve 1453 'ten sonra Moskova'nın Bizans mirasına söylem düzeyinde sahip çıkması ${ }^{3}$ gibi örneklerden anlaşılabilen Gritchenko'nun hissettiği tarihi bağlar; diğeri ise kendi sanat üslubu dolayısıyla Bizans'ı keşif arzusudur.

\section{Gritchenko'nun Rus tarihinde Bizans'ı Görüşü}

Gritchenko 3 Nisan 1920'de Ayasofya’yı ziyaret ederken şu sözleri sarf eder:

Bugün Ayasofya gözüme her zamankinden daha yüce, daha muhteşem göründü! Vladimir Kievski'nin elçilerinin ayin sırasında niye "Nerede olduğumuzu bilemiyoruz, gökte miyiz yerde miyiz!" diye haykırdıkları anlaşılıyor. ${ }^{4}$

Vladimir Kievski (hük. 980-1015) Kiev Ruslarının Knezi olarak 988'de Ortodoksluğu kabul ederek Rus kültürünün uzun yıllar Bizans ile önemli bir paydada birleşmesine yol

1 Alexis Gritchenko, Deux ans à Constantinople (Paris: Quatre Vents, 1930); Alexis Gritchenko, İstanbul'da İki Yll 1919-1921: Bir Ressamin Günlügü̈, çev. Ali Berktay (İstanbul: Yapı Kredi Yayınları, 2020).

2 Nilüfer Şaşmazer, haz., Alexis Gritchenko: İstanbul Yılları (İstanbul: Vehbi Koç Vakfi, 2020), 307.

3 1510'da keşiş Pskov'lu Philotheos III. Vassili’ye hitaben "İki Roma düştü ve üçüncüsü ayakta. Bir dördüncü olmayacak.” der. Kastettiği üçüncü Roma, Moskova’dır. Bkz. John Meyendorff, „Eastern Orthodoxy, “Encyclopedia Britannica, erişim tarihi 31 Ocak 2020. https://www.britannica.com/topic/Eastern-Orthodoxy. 
açtı. Gritchenko'nun bahsettiği Vladimir elçilik heyetinden, ilk olarak on ikinci yüzyıl başında yazıldı̆̆ı düşünülen Birincil Rus Kronik' ${ }^{5}$ adlı kaynaktan haberdar olunur. Kronik'e göre Vladimir çevresindeki ülkelere elçiler göndermiş, bunların, ziyaret ettikleri ülkelerin medeniyetine ve dinine dair raporlar vermesini istemiştir. Bizans İmparatorluğu'nu ziyaret eden heyet Ayasofya'nın şaşaası ve heybetinden etkilenmiş, buradaki ayinleri zarif bulmuştur. Kronik, Vladimir'in Ortodoksluğu kabulünü bu karşılaşmayla gerekçelendirir. ${ }^{6}$

Gritchenko'nun Ayasofya'yı bu ziyareti ilk değildi, ressam senenin başından beri tekrar tekrar Ayasofya'ya girmişti fakat bu sefer bu aşkınlık hissine kapıldı. Yaşadığı bu deneyimi Ayasofya'nın kendinden bin sene önceki ziyaretçilerinin hisleriyle açıklayan Gritchenko, bu alıntısıyla, zamanlar arası bir duygudaşlık sürekliliği kurar. Var olduğunu iddia ettiği Rus zihnindeki sürekliliği, Ayasofya'nın etkisinin kesintisiz varlığını Günlük'ün girişinde de şöyle belirtir:

Bizans kültürünün ve zihniyetinin alametifarikası olan Ayasofya'ya ilişkin fikriyatın asırdan asıra, nesilden nesile Rus bilincine nasıl nüfuz ettiğini anlatmak için ciltlerce kitap yazılabilir. ${ }^{7}$

Ressam benzer bir duygudaşlığı—Ayasofya'ya yönelik heyecanı-deniz yoluyla şehre yaklaşırken gördüğü manzarayı tarif ederken de yaşar, Ayasofya bu anda da ufuk çizgisindeçizgi Vladimir'in elçilerinin gördüğünden çok başka olsa da — Gritchenko'nun dikkatini çeken yapıdır. ${ }^{8}$ Ayasofya, Günlük'te hem Gritchenko'nun zihnini kurcalaması hem de en sık uğradığı güzergahlardan biri olmasıyla İstanbul yıllarının abidesidir.

\section{Konstantinopolis'in Gritchenko'ya "musallat oluşu”}

Gritchenko, İstanbul seyahatinden çok önce, Moskova'da Ayasofya’yı hayal edişini şöyle anlatir:

Bir arkadaşımın bana Moskova'da Ayasofya'yı göstermeyi önerdiği günü hiç unutmayacağım. Çok aşağılara inen bir sokaktan (Karetni Riad'ın arkasında) bana eski evler ve yapılardan oluşan bir bina adacığını işaret etti; uzaktan bakınca, damları, duvarları ve piramit biçimindeki kavak ağacıyla Ayasofya panoramasını çağrıştıran yanları vardı. ${ }^{9}$

Ayasofya'nın ve Konstantinopolis'in Rus toplumsal hafızasındaki sürekliliğinin yanında, Gritchenko'nun kişisel ilgisi de başta Ayasofya'ya ve Bizans tarihine, hayatının erken bir döneminde yönelmiştir. Arkadaşıyla Moskova sokaklarında Ayasofya’nın siluetine bakışı günlüğünde aktardığı kadarıyla münferit bir vaka değildir. Gritchenko, günlüğünün yazım

5 Bkz. "Laurentian Codex" (1377), F.p.IV.2, National Library of Russia, St. Petersburg.

6 "Sonra Bizansa gittik ve Yunanlılar bizi tanrılarına ibadet ettikleri binalara götürdüler. İşte o zaman gökte (cennete) miydik yoksa yeryüzünde mi bilemedik. Nasıl tarif edeceğimizi şaşırdık öyle ki yeryüzünde böylesi şaşaa böylesi güzellik yoktur. Bir şeyden eminiz ki orada tanrı insanların arasındadır ve onların ibadetleri başka halkların törenlerinden daha zariftir." Bkz. "Laurentian Codex" (1377), F.p.IV.2, National Library of Russia, St. Petersburg, f.v. л. 37.

7 Gritchenko, Günlük, 13.

8 Gritchenko, Günlük, 30.

9 Gritchenko, Günlük, 97. 
amaçlarından biri olarak şunu söyler: "Burada çocukluğumdan beri bana bir hayalet gibi musallat olan Konstantinopolis'i gün be gün nasıl keşfettiğimi anlatıyorum." ${ }^{10}$ Bu musallatlık, Gritchenko'yu Moskova sokaklarında olduğu kadar 1913'teki İtalya gezisinde de takip etmiştir. Bir mektubundan, Gritchenko'nun Arezzo'daki Aziz Francesco Bazilikası'nı ziyareti sırasında içeride restorasyon yürütüldügünü öğreniyoruz. Bu çalışmalar öyle görünüyor ki ressamı izlemeye geldiği eserin önünde zamanın akışını kaybetmekten alıkoymamıştır.

O günlerde Arezzo Kilisesi'nde Piero della Francesca'nın freskoları restore ediliyordu. Alexis fresklere yakından bakmak için yapı iskelesinin merdivenlerini usulca çıktı. Aşağıdan bir fisıltı duydu: "Aşağı inme vakti bayım. Kapatıyoruz." 11

Gritchenko'yu, önünde tefekküre

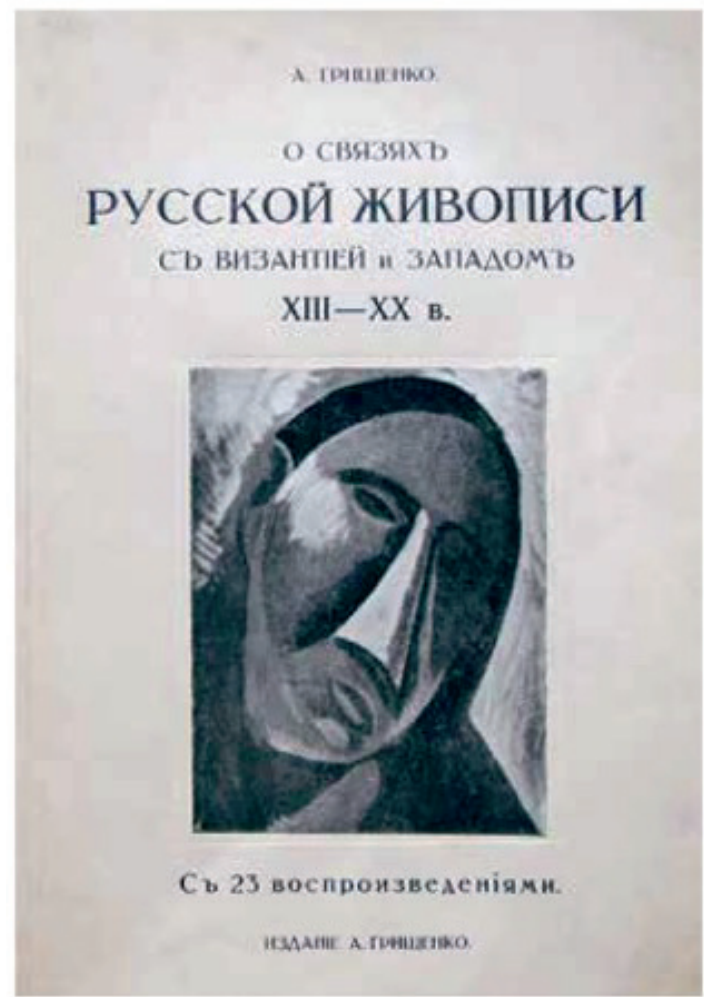

Figür 1: Gritchenko'nun Rus Resminin Bizans ve Batı ile İlişkisi kitabının kapağı. (Alexis Gritchenko: İstanbul Yıllarl, Meşher, 2020) dalmak için restorasyon iskelesini tırmanmaya iten Piero della Francesca freskoları Kutsal Haç Efsanesi çevrimiydi. 1457 yılında ${ }^{12}$ Bacci aile şapeli dekorasyonu için hayata geçirilen proje, üç duvar ve üç farklı seviyede Adem'in Ölümü ve Gömülüşü, Seba Melikesi’nin Kutsal Haça Tapınması, Konstantinos ve Maxentius'un Savaşı (Milvius Köprüsü Savaşı), Kutsal Haçın Gömülmesi, Konstantinos'un Rüyası, Kutsal Haçın Coşkuyla Karşılanması, Kutsal Haçın Bulunuşu, Herakleios ve Hüsrev'in Savaşı, (Yahudi) Judas'a İşkence Edilmesi ve Meryem'e Müjde sahnelerini barındırır. Çevrim, Eski ve Yeni Ahit sahneleri kadar Bizans tarihinden sahneler de barındirır (Konstantinos ve Maxentius'un Savaşı, Konstantinos'un Rüyası, [Yahudi] Judas'a İşkence Edilmesi, Kutsal Haçın Bulunuşu, Herakleios ve Hüsrev'in Savaş1). Gritchenko İtalya gezisini Rönesans sanatı çalışmalarına devam

10 Vita Susak, “Alexis Gritchenko: Selam Sana İstanbul!,” Alexis Gritchenko: İstanbul Yılları içinde, haz. Nilüfer Şaşmazer (İstanbul: Vehbi Koç Vakfi, 2020), 58.

11 Susak, "Selam Sana İstanbul," 42

12 Eserin yapılış tarihine yönelik tartışma için bkz. James Beck, "Piero della Francesca at San Francesco in Arezzo: An Art-Historical Peregrination," Artibus et Historiae 24, no. 47 (2003): 51. 
etmek ve bu gezi sonrası yazacağı kitabı Rus Resminin Bizans ve Batı ile İlişkisi'ni ${ }^{13}$ tamamlamak için yapmıştır ve hiç şüphesiz bu çevrim karşısındaki tefekkür hali, bir Rönesans başyapıtıyla karşı karşıya kalmış olmasından kaynaklanabilir, ancak kitabının Rönesans, Bizans ve Rus sanatını karşılaştırdığı ve Gritchenko'nun çocukluğuna dayanan Bizans ilgisi hesaba katılırsa burada gördüğü Bizans tarihine dair sahnelerden etkilenmiş olduğu da düşünülebilir.

Gritchenko'nun Bizans'a olan ilgisinin kendi sanat anlayışıyla bağının belirgin bir örneği Rus Resminin Bizans ve Batı ile İlişkisi kitabı için kapak resmi tercihidir. Ressam, 1913'te yayımladığı kitabının kapağına Picasso'nun Baş adlı eserini koymuştu (F.1). Susak'a göre bu provokatif bir harekettir ${ }^{14}$ ve kendisini de dahil hissettiği modernist sanatın, ikona üretimiyle diyalektik bir ilişkisi olduğu iddiasını taşımaktadır.

Ressam, günlüğünün pek çok yerinde sanatın köklerden beslenmesi gerektiğini vurgular; bunu hem kendi sanatı için hem de Osmanlı tebaasından meslektaşlarına kendisinin Osmanlı sanatının özü olarak tanımladığı eski halk sanatlarını daha çok çalışmalarını ve bundan faydalanmalarını salık vermek için yapar. ${ }^{15}$ Gritchenko'nun ikona sanatı hakkındaki uzmanlığının teknik bir yön de taşıdığını söyleyebiliriz. Rus ikonacılığının günümüze kalan önemli eserlerinden Vladimir Meryem'inin (F.2) temizlenmesinde Gritchenko'nun çalıştığını biliyoruz. ${ }^{16}$ Bu gibi görevler onun resmetme tekniğine de katkıda bulunmuş olabilir. Ayrıca, Gritchenko'nun çağdaşı, meslektaşı ve dostu Vladimir Tatlin'in Madonna eseriyle Vladimir Meryem'i arasındaki benzerlik dikkat çekicidir (F.2-3). ${ }^{17}$

13 Alexis Gritchenko, O sviaziakh russkoi zhivopisi s Vizantiei i Zapadom XIII-XX vv: Mysli zhivopistsa [Rus Resminin Bizans ve Batı ile İlişkisi, 13.-20. Yüzyıllar: Ressamın Görüşleri] (Moskova: 1913).

14 Susak, "Selam Sana İstanbul," 41.

15 Gritchenko'nun bu önerileri için bkz. Gritchenko, Günlük, 214. Ayrıca bu tartışmanın detaylı bir incelemesi ve İbrahim Çallı üzerindeki etkisi için bkz. Ayşenur Güler, "Alexis Gritchenko’nun İstanbul Yıllarının İzinde," Alexis Gritchenko: Istanbul Yılları içinde, haz. Nilüfer Şaşmazer (İstanbul: Vehbi Koç Vakfı, 2020), 149, 150.

16 Susak, "Selam Sana İstanbul," 36.

17 Tatlin' in bu eser için kaynaklarına dair tartışma için bkz. Roland Betancourt ve Maria Taroutina, haz., Byzantium/ Modernism: The Byzantine as Method in Modernity adlı kitabinda Explanation of the Cover (Leiden: Brill, 2015), XXIII. 


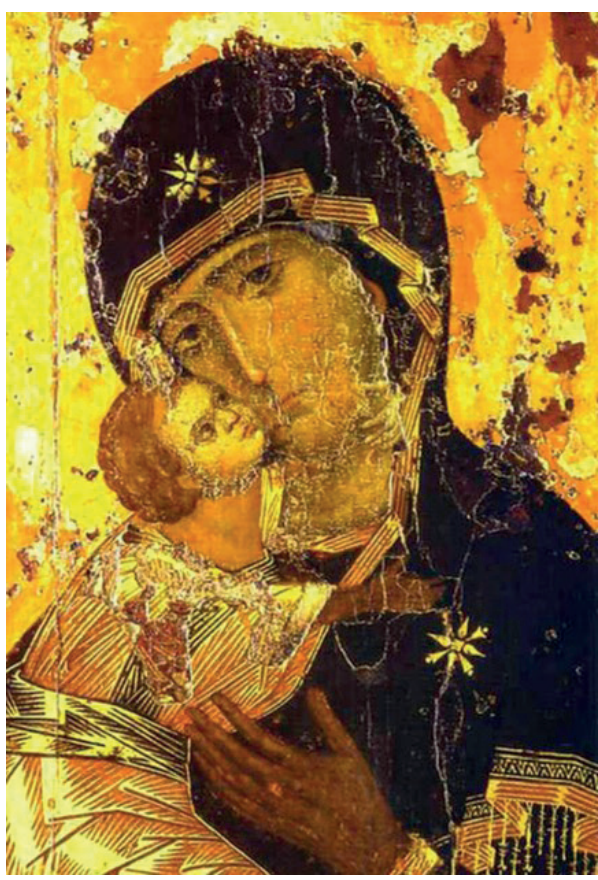

Figür 2: Vladimir İkonast,

Konstantinopolis, 1131 civar1, Tretyakov Gallery

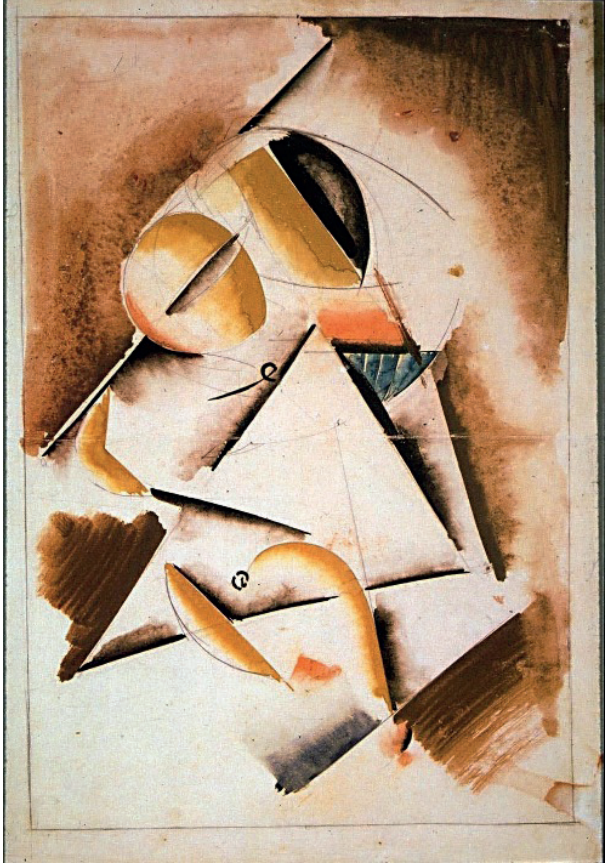

Figür 3: Madonna Kompozisyon Etüdü, Vladimir Tatlin, 1913. Kunsthalle Düsseldorf

Gritchenko'nun sanat anlayışındaki Bizans etkisi, döneminin bir ürünüdür ve GritchenkoTatlin'in eserinde de görüldüğü gibi-bu anlamda üretim yapan tek kişi değildir. On dokuzuncu yüzyıl ortası itibariyle başlayan Bizans'ın arkeolojik ve akademik anlamda yeniden keşfi ${ }^{18}$ bu dönemin sanatçılarının çeşitli gerekçelerle Bizans temalarını kullanmalarına olanak sağladığı gibi, genel bir ilginin de oluşmasını sağladı. ${ }^{19}$ Örneğin Vasily Kandinsky modern sanatın gelişiminde Bizans sanatının etkisi olduğu görüşüne sahiptir. ${ }^{20}$

\section{Günlük: Tarihyazımından Faydalanan Tarihdışı Bir Anlatı}

Gritchenko, Bizans tarihinin akademik anlamda güncellik kazanmasıyla sanatçıların Bizans eserlerinden etkilenmesi süreçlerinin her iki kolunu da takip etmiş görünüyor. Sanat

18 Bu ilgi dolayısıyla İstanbul'da faaliyet gösteren uluslararası akademik kurumlar için bkz. Brigitte Pitarakis ve Olivier Delouis, haz., Discovering Byzantium in Istanbul: Scholars, Institutions, and Challenges, 1800-1955 henüz yayımlanmamış (İstanbul: İstanbul Araştırmaları Enstitüsü Yayınları, 2021).

19 Örneğin bkz. J. B. Bullen, "Byzantinism and Modernism 1900-14", The Burlington Magazine 141, no: 1160 (Kasım 1999): 665-675; Betancourt ve Taroutina, Byzantium/Modernism.

20 Henry Maguire'ın aktardığı şekliyle Wassily Kandinsky, Concerning the Spiritual in Art, çev. Michael Sadleir ve Francis Golffing (New York: Wittenborn, Schultz, 1947), 76; Henry Maguire, "Truth and Convention in Byzantine Descriptions of Works of Art," Dumbarton Oaks Papers 28 (1974), 113. 
alanında ressamın en azından Rusya' daki Bizantinizmin ${ }^{21}$ takipçisi ve parçası olduğu aşikâr. Öte yandan, Bizans, Rönesans ve Rus sanatını kıyasladığı eserinden de anlaşılabileceği gibi ressam akademik üretimi de takip ediyordu. Bu takibin izini Günlük'te kimi zaman ressamın atıfları sayesinde, bazen de olası kaynaklar üzerine düşünerek sürebiliyoruz. Gritchenko özelinde - frankofon olduğu ve ana dili Rusça olduğu için—Fransızca yazındaki gelişmeler ve Rusya'nın İstanbul'da kurduğu İstanbul Rus Arkeoloji Enstitüsü22 bu çalışmadaki kaynaklar arasında önemli yer teşkil eder. Bu yazının amaçlarından biri, Gritchenko'nun gezilerine dair verdiği bilgilerin kaynaklarını tespit edip, bu bilgilerin güncel durumunu değerlendirmektir. Bu esnada, Günlük'e dair gözden kaçırılmaması gereken bir özellik-Gritchenko gezileri esnasında gün gün tuttuğunu söylese de ${ }^{23}$ — eserin, ressamın İstanbul'dan ayrıldığg 1921 'den dokuz sene sonra 1930'da Fransa'da basılmış olmasıdır. Ressamın, çoğunluğunu Fransa'da geçirdiği bu dokuz yılda Bizans'a olan ilgisini kaybetmediği, orada İstanbul'daki çalışmalarını sergilediği ve hatta Charles Diehl'le irtibata geçmiş olabileceği biliniyor. ${ }^{24}$ Dolayısıyla basım öncesi günlüğünü gözden geçirmiş, yeni bilgiler eklemiş veya var olan bilgilerini güncellemiş olabilir. Bu ihtimal, akademik kaynakları açısından, günlüğün tutulduğu esnada olduğundan daha zengin bir şekilde basılmış olabileceğini akla getiriyor.

Gritchenko'nun anlatısında, mimarlık tarihi farkındalığı, tarihsel süreklilik ve süreksizliklerçoğunlukla süreklilikler —şehri ilgilendiren Dördüncü Haçlı Seferi, Konstantinopolis'in Osmanlılarca fethi gibi tarihi vakaların birincil kaynaklara dayanılarak aktarımı ve son olarak da topografya temelli, onun geçirdiği dönüşüm—ya da tarih boyunca aynılığı—gibi özellikler öne çıkar. Gezinin duraklarında bu özellikler sıklıkla gözlenir.

Gritchenko, faydalandığını düşündüğüm bu kaynakları ve tarihsel farkındalığını reddeder. Ressam, René-Jean'a, basılan Günlük'ün bir kopyasıyla birlikte yolladığı mektubunda “Orada rehbersiz, kitapsız şekilde İstanbul'un çitlerinde halen kalbi çarpan Bizans ruhunu keşfettim"25 yazar. Ayrıca, Kara Surları'nı ziyaret ettiği bir esnada “[B]urada engel yok; ilim cemiyetlerinin

21 Bizantinizmi (Byzantinism), ortaçağcılık (Medievalism) anlamıyla kullanıyorum. Ortaçağcılık alanının en köklü akademik dergisi Studies in Medievalism, en geniş haliyle terimi şöyle tanımlıyor: "the study of responses to the Middle Ages at all periods since a sense of the mediaeval began to develop." Bu tanım, aynı zamanda ortaçağa yönelik bir bitmişlik ön görüyor. Bizantinizm için de Bizans İmparatorluğu fikrinin ortaya çıkmasından itibaren, yani imparatorluğun 1460'ta Trabzon ve Mora'daki uzantılarını da yitirmesinin ardından Bizans'a dair yapılan her türlü üretim bu tanımın içine girebilir. Ortaçağcılık tanımı için bkz. David Matthews, Medievalism: A Critical History (Cambridge: D.S. Brewer, 2015), 1. Bizantinizm alanında bazı çalışmalar için bkz. Przemysław Marciniak ve Dion C. Smythe, haz., The Reception of Byzantium in European Culture since 1500 (New York: Routledge, 2015); Alena Alshanskaya et al., haz., Imagining Byzantium Perceptions, Patterns, Problems (Mainz: Verlag des Römisch-Germanischen Zentralmuseums, 2018); Betancourt ve Taroutina, haz., Byzantinism/Modernism (Leiden: Brill, 2015); Marie-France Auzépy, haz., Byzance En Europe (Saint-Denis: Presses Universitaires Vincennes, 2003).

22 Enstitünün faaliyetleri için bkz. Pınar Üre, "Byzantine Heritage, Archaeology, and Politics between Russia and the Ottoman Empire: Russian Archaeological Institute in Constantinople (1894-1914)" (Doktora Tezi, The London School of Economics and Political Science, 2014).

23 Gritchenko, Günlük, 17.

24 Susak, "Selam Sana İstanbul," 64.

25 Susak, "Selam Sana İstanbul," 58. 
varlığı hissedilmiyor, rehberlerin sesi duyulmuyor, turist yok, ne bir sınır var ne de kısıtlama..."26 yazarak, özgürce gezebildiğine, formel araştırmanın ve yirminci yüzyıl başında artık iyice yaygınlaşmış turizmin getirdiği yeniliklerden uzak olabildiğine sevinir. Bu cümleleri sarf etmeden hemen önce Harbiye'de geçirdiği boğucu günlerden bahsedip, ardından da Tarihi Yarımada için "Burası Avrupa'da, İtalya' da olduğu gibi değil. Her adımımı kendi irademe, arzuma, bazen tamamen sezgilerime göre atabiliyorum." ${ }^{27}$ diye ekler. Ancak Gritchenko, bahsettiğim ve örneklerini göstereceğim gibi, akademik yazın ve ilim cemiyetlerinin faaliyetleriyle, en azından doğrudan İstanbul Rus Arkeoloji Enstitüsü’nün faaliyetleriyle, gezileri esnasında bağını koparmamıştı. Ressamın bu romantik üslubu, belki kaynak kullanımını gizler ama bu üslubun tarihyazımı ve şehri algılayışıyla ilgili düşüncelerini yansıttığını söylemek gerekir. Gritchenko, dönemin İstanbul'una dair klişeleşmiş Pera-Suriçi karşıtlığını-farklı bir yönden de olsa — benimser. ${ }^{28}$ Ressamın İstanbul'u — anlatmaya ve resimlerinde tasvir etmeye değer gördüğü alan - çoğunlukla Suriçi’nden ibarettir. Bu Suriçi fazlasıyla anakronik, Osmanlı ve Bizans'ın, bina ve doğanın, insan ve ikonanın iç içe geçtiği, birbirinin parçası olduğu büyülü bir bölge şeklinde tasvir edilir, hem Günlük'te hem de Gritchenko'nun bu bölgeyi betimlediği resimlerde bu niteliğe şahit olabiliyoruz. Gritchenko’nun anlattıkları özelinde örnekler verip bunların nasıl bir tarih anlatısına dönüştüğünü göstermeden önce, günlükten çarpıcı ve Suriçi'nin tüm duygusunu belirleyen şu uzunca bölüme bakalım:

Eski köprü'de [Unkapanı Köprüsü] demir korkuluğa sırtını yaslamış, beyaz çarşafına sık1 sıkı sarınmış bir dilenci kadın. Tek gözü açık. Kısık, zor duyulan bir sesle mırıldanıyor: Allah Allah... Diğer tarafta bir falcı kadın renkli bakla tanelerini, çakıl taşlarını yere yayıyor (tırnaklarını kınayla kırmızıya boyamış). Önüne çömelmiş bir askerin eline bakıp istikbalini anlatıyor. Bir arzuhalci, ihtiyar bir hoca Çin fermanlarına benzeyen, kanarya sarısı fonlar üzerinde gümüş aylar taşıyan katlanmış kâğıt yapraklarını kehanet yazacakmış gibi açıyor. Bir kayıktan bir türkü yükseliyor. Pruvaya oturmuş Türk kadını başının üzerine kaldırdığı siyah yaşmağının uçlarını rüzgara bırakmış, uçuşuyorlar. ${ }^{29}$

Gritchenko, bir öğretmeninin, Londra'da bir dilenci sokakta şarkı söylese hemen hapse atılır dediğini hatırlatarak zaten anın ilk sahnesinden Suriçi ve Avrupa karşıtlığını verir, söz konusu İstanbul'ken bu karşıtlık hep Pera-Suriçi karşıtlığı olarak görünüyor. Ressamın Eski Köprü üzerinden geçişi, Tarihi Yarımada’ya yaptığı yolculukları hem coğrafi hem de kronolojik bir harekettir. Gritchenko, oraya adım attığında, oradan bahsettiğinde, zamanı Bizans’tan Osmanlı'ya doğru hafif bir akışın olduğu ama aslen durağan bir Bizans/Osmanlı anı şeklinde tecrübe eder.

26 Gritchenko, Günlük, 139.

27 Gritchenko, Günlük, 139.

28 Gritchenko'nun Pera- Suriçi karşıtlığına dair düşünceleri için bkz. M. Baha Tanman ve K. Mehmet Kentel, “Alexis Gritchenko: İşgal Dönemi İstanbulu'nda Gündelik Yaşam,” 26 Haziran 2020, Meşher Podcast adlı podcast içinde, haz. Karoly Aliotti, Şeyda Çetin ve Ebru Esra Satıc1, 32:00-35:00, https://open.spotify.com/ep isode/2vhhLFbAhBaBDsLfRpe43R?si=BxEo0ZrxSp-16SFJiGI5Dg.

29 Gritchenko, Günlük, 147. 


\section{Bizans'la Karşılaşma}

Gritchenko için Bizans Konstantinopolis’i ile karşılaşmanın yarattığı intibanın öne çıkan bir unsuru pembe rengidir. Pembe, Konstantinopolis'in Bizans mirasının ortak bir ögesi ve Gritchenko'nun yazılı kaynaklarıyla bunların seyahatinde tuttuğu yerin de belirgin bir örneğidir. Günlük’te pembeyi şöyle tanımlar ressam:

Pembe Şark'ın rengidir, Bizans mirasıdır. Hem Rus ikonaları hem de İncillerdeki minyatürler bu renkle doludur; kiliselerimiz ve manastırlarımız bu renge boyanmıştır. ${ }^{30}$

1923 'te, İstanbul resimlerinden oluşan Paris sergisinin de adını Constantinople Bleu et Rose (İstanbul Mavi ve Pembe) ${ }^{31}$ koyan ressamda bu rengin bıraktığı güçlü intiba açıktır. Ancak bu, yalnızca şehri tecrübe edişine dayalı bir intiba değil, Bizans’a dair yazınla olan yakın ilişkisinin de bir sonucudur. Gritchenko'nun İstanbul gezisi esnasında zaman zaman göreceğimiz gibi rotası konusunda pek çok başka yazarla birlikte, ${ }^{32}$ Theophile Gautier'ye olası atıfları vardır. ${ }^{33}$ Paris’teki serginin kataloğuna önsöz yazan André Levinson, Gritchenko'nun, Gautier'nin 1852'de kaleme aldığı Baiser rose, baiser bleu (Pembe Buse, Mavi Buse) şiirinden esinlendiğini öne sürer. ${ }^{34}$

Günlük’te Gritchenko'nun en sık ziyaret ettiği yapı Ayasofya'dır. Gritchenko'nun yapıya gezilerinin, burayla ilgili anlattıklarının irdelenmesi, onun Bizans Konstantinopolis'ini algılayışı, şehir hakkında okudukları gibi detayları açık etmede etkilidir. Ressam, yapının tarihsel katmanlarının farkında olmakla birlikte bazen de yorumlarında anakroniktir. Sözgelimi, spolia sütun kullanımının farkındadır ve bunu bildirir; Artemis tapınağı ve Mısır Heliopolis'inden gelen sütunlar1 ${ }^{35}$ tespit eder. Bu devşirme sütunların oluşturduğu görüntünün sütundan bir ormanı andırdığını söyler. ${ }^{36} \mathrm{Bu}$ şiirsel betimleme, duygusal bir anın dışavurumu gibi görünse de olasılıkla altıncı yüzyılda inşa edilen İustinianos Ayasofya'sının açılışında ekphrasis okuyan Paulos Silentarios’tan esindir. Silentarios Ayasofya'nın sütunlarından bahsederken şu sözleri kullanır:

30 Gritchenko, Günlük, 45.

31 Susak, "Selam Sana İstanbul," 56. Mavi de Osmanlı’yı tanımlar, bkz. Susak, "Selam Sana İstanbul," 47.

32 Tarkan Okçuoğlu ve Emir Alışık, "Alexis Gritchenko: İstanbul Mavi ve Pembe,” 8 Kasım 2020, Meşher Podcast adlı podcast içinde, haz. Karoly Aliotti, Şeyda Çetin ve Ebru Esra Satıc1, 5:41-7:00, https://open.spotify.com/ episode/5genRTToiPvMjVc781wKVw?si=0kkYqJnRSKOst5b4g-BABA.

33 Örneğin, Aya İrini'de bulunan askeri müzeyi gezerken eserleri anlatışı Gautier'nin anlatımıyla benzeşir. "Sol nefte Mehmed'in, Muhteşem Süleyman'ın kılıçları, Arnavut kahraman Sender [İskender] Bey’in kılıcı, Tanurban'ın [sic] kol zırhları." Bkz. Gritchenko, Günlük, 206. "There we saw the sabre of Mahomet II [...] an enamelled armlet of Tamerlane, and a battered sword, of iron, with cross-handle, once wielded by the renowned Scanderbeg." [Orada II. Mehmet' in kılıcını gördük (...) Timur'un parlak kolçağını, zamanında ünlü İskender Bey’in kuşandığı haçvari kabzalı tahrip olmuş bir demir kılıç (gördük)] Bkz. Theophile Gautier, Constantinople of To-day, çev. Robert Howe Gould (Londra, David Bogue, 1854), 295. Tarkan Okçuoğlu ve Emir Alışık, "Alexis Gritchenko: İstanbul Mavi ve Pembe," 8 Kasım 2020, Meşher Podcast adlı podcast içinde, haz. Karoly Aliotti, Şeyda Çetin ve Ebru Esra Satıc1, 5:41-7:00, https://open.spotify.com/episode/5genRTToiPvMjVc781wKVw?si=0kkYqJnR SKOst5b4g-BABA.

34 Susak, "Selam Sana İstanbul," 47

35 Gritchenko, Günlük, 121.

36 "Üst galerilerin bulunduğu kattaki dağılım da alt katla aynı. Aşağıdakilerden daha alçak granit, porfir ve mermerden altmış sütun olağanüstü bir orman oluşturuyor.” Bkz. Gritchenko, Günlük, 50. 
Geniş oylumlu tapınağın orta mekânıyla, uzun komşu sahının kapalı alanını bu sütunlar ayırmış işte. Bugüne dek yontulmamış Molossia toprağında böylesi; sorgucu bunca soylu, ormanlar (gibi) renkli, üstü baştanbaşa çiçek, böyle sütun işlenmemiş. ${ }^{37}$

Bizans yazınına ve yapıda kullanılan malzemelerin kökenine dair bu bilginin yanında Gritchenko'nun mimari gözlemi de isabetli ve jargona hakimdir. Ressamın 1 Ocak 1920'deki ziyaretinde yapının mimari tarifi şöyledir:

Yetmiş yedi metre uzunluğa yetmiş bir metre genişlik. Üzerine bindirildiği devasa küp iki yan nef, dört ara geçit ve bir naosa bölünmüş. Dört ana ayak kusursuz bir dörtgen oluşturuyor; bu dörtgenin üstü köşeleri perde gibi aşağı inen dört muazzam kemerle kapatılmış. Doğrudan bu kemerlerin üstüne bindirilen kubbe, ayaklar arasında kalan dikdörtgene tam uyuyor ve kiliseye altmış beş metre [sic] yukarıdan bakıyor. Daha aşağıda, ana kubbenin batısında ve güneyinde birbiriyle eşit çaplarda iki yarım kubbe var; daha aşağıda da apsitlerin küçük yarım küreleri bunlara ekleniyor. Yan nefler ve apsitler naostan ayakların arasına yerleştirilmiş on altı yeşil somaki sütunla ayrılıyor. Her apsitin arkasında muhteşem mor mermerden iki sütun yer alıyor. Ara geçitlerin ve neflerin dibinde çok sayıda sütun, kubbeleri ve kemerleri destekliyor. ${ }^{38}$

Bu detaylı gözlem ve teknik anlatı kabiliyetinin yanında, Gritchenko'nun mimari tarihine yönelik kimi sezgileri bugün modern mimarlık tarihyazımında yer buluyor. Örneğin, “Ayasofya, İslam'ın [Osmanlı'nın] tüm camilerinde örnek alınmıştır. Galiplerin [Osmanlı'nın] fanatizmi bile Ayasofya'ya boyun eğmiştir." ${ }^{\text {"39 }}$ çıkarımı, yankısını günümüzde mimari tarihi çalışmalarında bulur. $^{40}$

Ayasofya'yla karşılaşmada gördüğümüz kaynak kullanımını Konstantinopolis'in Osmanlı tarafından ele geçirilişini anlattığı bölümde de görüyoruz. Bu yazıda başka örnekleri de görülecek olan, bazen büyük alıntılarla bazen ressamın kendi diliyle aktardığı tarih anlatıları Günlük'ü hatıra anlatısının dışına çıkarıp bir tarih kitabı ya da kronik okunduğu hissini uyandırır. $\mathrm{Bu}$ bölümler, aynı zamanda Günlük'ün yayımlanmadan önce gözden geçirilip eklemelere maruz kalmış olduğu ihtimalini de güçlendirir. Çünkü, Gritchenko İstanbul'dayken bazı kitaplar okuduğundan söz etse de bu alıntılarda gördüğümüz kitaplara ulaşabilecek durumda olup olmadığı net değildir. Gritchenko'nun 1453 anlatısı, bir on altıncı yüzyıl Rus kroniği olan Voskresenskaya Kroniği'nden büyük bir alıntı içerir. ${ }^{41} \mathrm{Bu}$ alıntının hemen ardından Bizans'a “Latinler”den gelmeyen yardımdan bahsederken 1439'da tamamlanan Floransa Konsili'nin tarihini hatalı verir (1449) ve "Papaların külahındansa Türklerin sarığı evladır" sözünü hatalı bir şekilde XI. Konstantinos Palaiologos'a atfeder. ${ }^{42} 1453$ 'e dair anlatının bir başka kaynağ 1

37 Mabeyinci Pavlos, Ayasofya 'nın Betimi, çev. Samih Rifat (İstanbul: İstanbul Araştırmaları Enstitüsü Yayınları, 2010), satır 545.

38 Gritchenko, Günlük, 49.

39 Gritchenko, Günlük, 17.

40 Konunun detaylı incelemesi için bkz. Gülru Necipoğlu, Age of Sinan: Architectural Culture in the Ottoman Empire (Chicago: The University of Chicago Press, 2005), özellikle The Süleymaniye Complex bölümü.

41 Gritchenko, Günlük, 176, 177. Voskresenkaya Kroniği için bkz. Русская летопись с Воскресенского списка [Voskresenkaya'dan Rus Kroniği], list. SPb., 1793-1794. Ch. 1-2; PSRL. SPb., 1856-1859. T. 7-8.

42 Gritchenko, Günlük, 178. 
P.A. Dethier'nin, fethi anlatan tüm birincil kaynakları toparlamaya giriştiği bitmemiş eseri olabilir. ${ }^{43}$ Macar Bilimler Akademisi için, Budapeşte' de veya Galata/Pera' da hazırlanan eserin bazı kopyaları çeşitli kütüphanelere gönderilmiş olsa da eser hiçbir zaman gerçek anlamda basılamadı. ${ }^{44}$ Gritchenko, Kara Surları'nın farklı kapılarında iki kez Dethier'den aktarım yapar, bunlardan biri de 1453'ün anlatılmasından hemen önce ve Mevlanakapı' daki yazıtlarla ilgilidir. ${ }^{45}$ Ayrıca, Gritchenko'nun aktardığı, kuşatma esnasında açık kalmış "Kirkaporta" [Kerkoporta] kapısından sızan elli yeniçeri pasajı, fethin çağdaşı kaynaklar arasında Doukas'ın kroniğinde ${ }^{46}$ anılır. Gritchenko Doukas'1 mı okudu, Dethier'in eseri içinde Doukas kısmına mı bakabilmişti, yoksa bu hikâyeyi tamamen başka bir ikincil kaynaktan mı aktardı bilmiyoruz, ancak Dethier'nin, 1453 anlatısında ressama kaynak olmuş olması ihtimaller arasındadır ve bu aktarım onun hatıra anlatısından sapıp kaynaklar kullanarak belli bir tarihsel olayı anlattığının göstergesidir.

\section{Tarihdıșılığın İzdüşümleri}

Yukarıdaki örneklerde gördüğümüz tarihsel ve terminolojik farkındalığa karşın, Günlük’ün anlatısı nostaljik bir süreklilik, hatta tarihdış1lı ${ }^{47}$ haline bürünebilmektedir. Gritchenko, bir gün batımında Ayasofya'nın kubbesi ve minarelerinin yarattı̆̆ 1 şsı oyunlarından bahsederken dördüncü yüzyıl azizi İoannes Khrysostomos'un "kutlu olsun dinginlik, kutlu olsun akşam” sözünü burada sarf etmiş olabileceğini söyler. ${ }^{48}$ Dördüncü yüzyılda Konstantinopolis patrikliği yapmış ve aziz ilan edilmiş olan Khrysostomos, Ayasofya'nın altıncı yüzyılda İoustinianos tarafından yaptırılmış ve günümüze kadar çeşitli onarımlar dışında aynı kalmış safhasını doğal olarak görmüş bile değildi. Kaldı ki Gritchenko'nun naklettiği manzarada Osmanlı dönemi minareleri ve onların yarattığı 1şık oyunları okuyucuya geçirilmeye çalışılan ve Khrysostomos'a da atfedilen duygu durumunun bir parçasıdır. Ressamın bu ilginç söylemi münferit ve basit bir tarih hatası değil, bilakis Günlük'e yayılan tarih anlayışının bir parçasıdır. Gritchenko'nun Konstantinopolis algısında Osmanlı müdahaleleri ve Osmanlı varlığı şehrin ayrılmaz bir parçası, bütün bir "Konstantinopolis" tarihsel ve duygusal bağlamının ayrılmaz bir unsuru olarak yer bulur. Burada gördügümüz Bizans-Osmanlı sürekliliği, hatta tarihdışı bir Konstantinopolis fikri, şehrin insanları veya belli sanat eserleri ve Ayasofya örneğindeki gibi anıtsal yapılarda

43 P. A. Dethier ve C. Hopf, haz., Monumenta Hungariae Historica. Ser. Scriptures (Masodik osztaly Irok). Vol. 22.1. (Galata/Pera ya da Budapeşte: 1872 ? ya da 1875?).

44 Marios Philippides ve Walter K. Hanak, The Siege and Fall of Constantinople in 1453: Historiography, Topography, and Military Studies (Farnham: Ashgate, 2011), 8.

45 Gritchenko, Günlük, 127, 174.

46 Doukas, Historia Turco-Byzantina, haz. Harry J. Magoulias (Detroit: Wayne State University Press, 1974$), 223$.

47 Historicism' in çağrıştırdığı, tarihin evrelerinin kendilerine has özellikler barındırması fikrinin tersine, unhistoric ve anachronistic. Burada historicism'i ilk anlamıyla, yani her dönemin kendi bağlamı içinde taşıdığı gerçekliği açısından kullanıyorum. Bkz. Ian Buchanan, "Historicism." A Dictionary of Critical Theory içinde (Oxford University Press, 2018). https://www.oxfordreference.com/view/10.1093/acref/9780198794790.001.0001/ acref-9780198794790-e-323.

48 Girtchenko, Günlük, 132 
sık sık karşımıza çıkar. Bu fikri, bu iç içeliği ressamın manzara çalışmalarında da görüyoruz. Bu iç içeliğin ve duygunun yaratılmasında duyumsallık vurgusu da oldukça güçlüdür. Örneğin; Ayasofya'da bir namaz vaktinin bitiş anın aktarılışına bakalım:

Yatsı namazında Ayasofya'daydım. Ana nefteki bir ayağın yanında, küçük bir kemerin altına bağdaş kurmuş, hiç çaktırmadan resim yapıyorum. Işık duvarlarda hareleniyor. Her şeyde bir kaygısızlık, bir mutluluk var. Kubbe yaldızlı bir örtü; imam tiz bir notayı zurna misali uzattıkça uzatıyor. Ses dalgaları uzamda eriyor. Kısa süren namaz bitti. Cemaat telaşsız, gruplar halinde dağılıyor. Açık renk cüppeler ve siyah, mavi veya beyaz şalvarlar giymişler. Mihrabın üzerine beni coşturan ton karışımları düşüyor. Renklerin derinliğini ve büyüsünü ifade etmek zor. ${ }^{49}$

Yapının farklı yüzeylerinde ışığın yansımalarına ve imamın sesinin dalgalanan hareketine, binayı terk eden rengarenk cemaatin telaşsız hareketliliği eklenir. Gritchenko, görsel ve işitsel bir dinamizmin tasviriyle duygu durumunu aktarırken, Bizans Konstantinopolis'ine değin kendisini hayatı boyunca en etkilemiş yapının içinde vuku bulan Osmanlı ritüelini bir harmoni içinde vererek, tarih anlayışını ele verir (F.4).

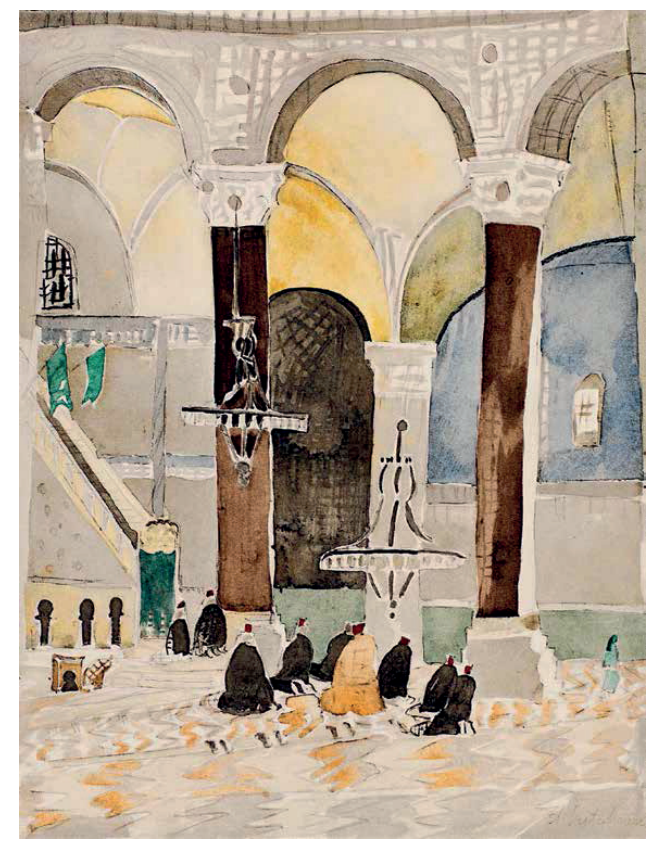

Figür 4: Alexis Gritchenko, Ayasofya. Deux ans à Constantinople. Paris: Quatre Vents, 1930. (Alexis Gritchenko: İstanbul Yılları, Meşher, 2020)

$\mathrm{Bu}$ durumun bir başka örneği surlar civarında başvurduğu tasvirlerde görülür. Surlardan bahsederken sarf ettiği "çok gerilerde kalmış çağların canlı atmosferini soluyoruz" ${ }^{50}$ gibi

49 Gritchenko, Günlük, 123.

50 Gritchenko, Günlük, 125. 
oldukça çelişkili bir ifadeyle surlara Bizans ve Osmanlı'yı bir araya toparlayan tek bir an yaratımında işlevsel bir görev verir.

Ön tarafta, bostanların devamında, güçlü Bizans surlarının şeridi uzanıyor; surlar Haliç’ten yukarı dönüp Tekfur Sarayı'nın bulunduğu yükseltiye doğru çıkıyor. Burçların ve devasa payanda duvarlarının (burada eskiden hendekler vardı) eteğindeki bahçelerde ve bostanlarda zamanla kararmış küçük evler yükseliyor. Surun üzerinde, tek minareli caminin sarı kübü çok yukarıdan görünüyor. ${ }^{51}$

$\mathrm{Bu}$ anlatıdaki, surlar $\longrightarrow$ Tekfur Sarayı $\longrightarrow$ burçlar $\longrightarrow$ sur önü bahçeleri ve bostanlar $>$ kararmış küçük evler $\longrightarrow$ surun üzerinden görünen tek minareli bir caminin gövdesi izleği hem çok eski hem de bugün de nefes alan bir Bizans-Osmanlı Konstantinopolis'i çizer. Bu yan yana, iç içe hal hem bu sözlü tasvirin bir ay ertesinde resmettiği eserde hem de sonraki sur manzaralarında görülebilir (F.5-6).

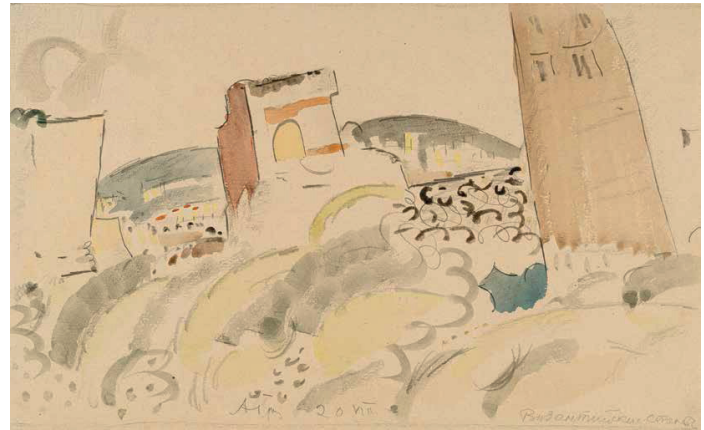

Figür 5: Alexis Gritchenko, İstanbul Surları (Bizans Surları), Ağustos 1920, Ukrayna Ulusal Sanat Müzesi Koleksiyonu. (Alexis Gritchenko: İstanbul Yılları, Meşher, 2020)

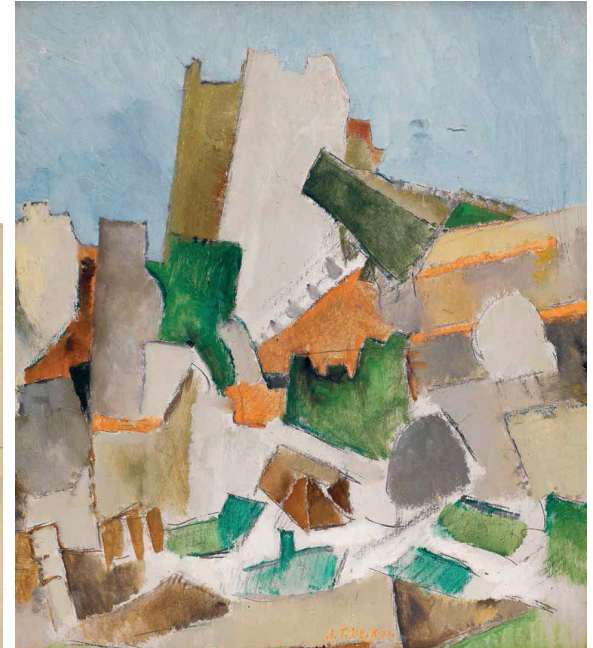

Figür 6: Alexis Gritchenko, İstanbul, Mart 1921, Ömer Koç Koleksiyonu. (Alexis Gritchenko: İstanbul Yillart, Meşher, 2020)

\section{Sokakların ve İkonaların İnsanları}

Sadece topografi ve mimarisiyle değil, Konstantinopolis, insanıyla da bu tarih anlatısında yer alır. Gritchenko'nun, Tarihi Yarımada'nın sokakları ve mabetlerinde rastladığı Osmanlılar yalnızca yirminci yüzyıl insanı değildir, ondan belki daha çok Bizans'ı da bir şekilde içinde barındıran garip bir tarihsel tiptir. Sokakta karşılaştığı Osmanlı kadınları genelde orans pozisyonunda Meryem'i andırır. II. Mehmed'in türbesi başında dua eden kadın, ${ }^{52}$ Ayasofya

51 Gritchenko, Günlük, 119.

52 "Bir Türk kadın dindarca bir hürmet içinde açık pencerenin önünde duruyor; ellerini birleştirmiş dua okuyor; 


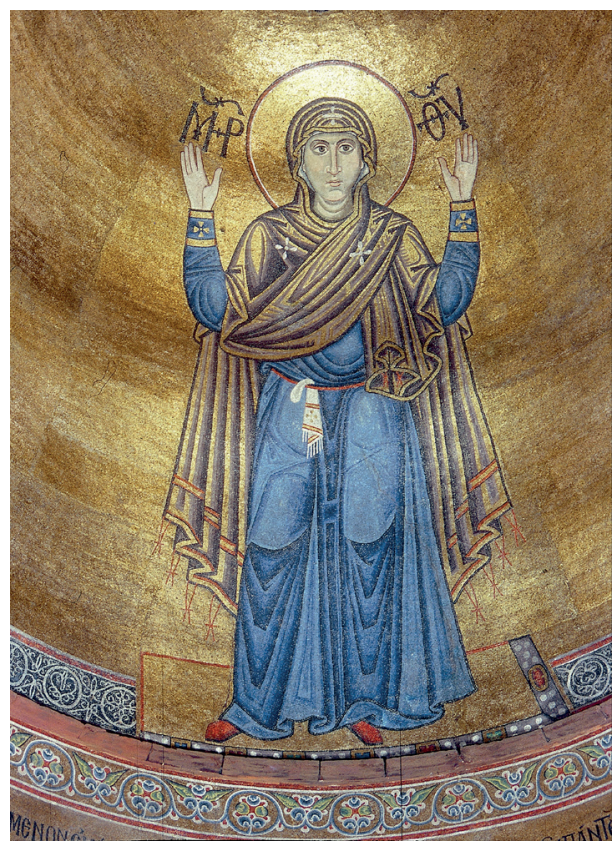

Figür 7: Orans pozisyonunda Meryem, Ayasofya, Kiev, 11. yüzy1l. National Conservation Area "St. Sophia of Kyiv". https://g.co/arts/JsavS8bt3ntPBmcC9 erişim tarihi: 24.10 .2020 yakınında bir başka türbe başında dua eden $\operatorname{kad} n^{53}$ tanımlamalarını yaparken, aklında Latince kelimenin "dua eden kişi” anlamından ziyade erken Hristiyanlık ikonografisinden beri görülüp, zamanla Meryem'in bir duruş tipine dönüşen ${ }^{54}$ bu ikonografi tipi olmalıdır. Özellikle de Kiev Katedrali'ndeki anıtsal boyutlardaki mozaik (F.7) ve Ayasofya'da neredeyse kaçamak bir şekilde görmeyi başardığı orans mozaiğini düşündüğü öne sürülebilir. ${ }^{55}$ Sadece kadınlar değil, erkekler de bu benzetmelerin konusu olur; bir Türk atlısını Aziz Georgios'a, ${ }^{56}$ “zenci gibi siyah yüzlü sakalsız bir Arap"1 Havari Matta’ya benzetir, ${ }^{57}$ camiye yönelen insanların yüzleri "tıpkı ikonalardaki gibi yanık toprak rengidir." Günlük'te, sokaktaki insan, ikonalarda rastlanan temalar ve Hristiyanlık tarihinden kişileri anımsatarak, tıpkı surlar meselesindeki gibi "çok gerilerde kalmış çağların canlı atmosferini” üretir.

"Orante" [Dua Eden Kadın] ikonasındaki Bakire Meryem'in yaşayan imgesi sanki.” Bkz. Gritchenko, Günlük, 104.

53 "Sokakta, parmaklığın yanında, güzel bir Türk kadını ellerini bir Orante ikonası misali öne uzatmış, telaşla dua mırıldanıyordu." Gritchenko, Günlük, 199.

54 Annemarie Weyl Carr, "Orans," The Oxford Dictionary of Byzantium (Oxford: Oxford University Press, 1991). Erişim tarihi 03.02.2021. https://www.oxfordreference.com/view/10.1093/acref/9780195046526.001.0001/ acref-9780195046526-e-3962.

55 "Sunakta durup apsitin derin yarım küresine bakıldığında, sanki sisin içinden çıkıyormuş gibi beş metre boyunda kolları açık bir silüetin belirdiği görülür. Bu, Orante tasviridir. Mozaiğin bu yarı gizli yaşamında mistik bir yan var. Kentin koruyucusu olan, halk ve ressamlar tarafindan en çok sevilen Panagia [Meryem] figürü asırlardır Büyük Kilise'nin gizli bir köşesinde görünmez bir biçimde yaşıyor." Gritchenko, Günlük, 124.

56 Gritchenko, Günlük, 98.

57 Gritchenko, Günlük, 166. Oysa Havari Matta Bizans sanatında genelde gri sakallı bir erkek olarak tasvir edilir. Bkz. Johannes Irmscher, Alexander Kazhdan ve Annemarie Weyl Carr, "Matthew," The Oxford Dictionary of Byzantium içinde (Oxford: Oxford University Press, 1991). Erişim tarihi 03.02.2021. https://www.oxfordreference. com/view/10.1093/acref/9780195046526.001.0001/acref-9780195046526-e-3390.

58 Gritchenko, Günlük, 144. 


\section{İbadet ve Sanat}

Gritchenko, Osmanlı sanatında ve Osmanlı İstanbul'unun bazı tarihsel travma anlarında da Bizans'll öncüller görür. Bu öncüllük ve devamlılık ilişkisinin örneklerinden biri, Gritchenko'nun Bizans mozaiği ile Osmanlı çinisinin Bizans ve Osmanlı toplumları için aynı şey olduğunu öne sürüşüdür. Hürrem sultanın türbesini ziyaret ederken şunları aktarır:

[T]ürbenin duvarı boydan boya İran [sic] çinileriyle kaplanmış. Ahenkli kontrastları içinde aydınlık tonlar: Mavi, nar kırmızısı, turkuvaz, bakırtaşı yeşili. Beyaz fon üzerine siyah saplara yerleştirilmiş çiçekler ve yapraklarla bezenmişler. Bizim atalarımız için ikona neyse, bir Müslüman için de çini levha aynı şeydir. Mütefekkir ve soyut, naif ve ciddi İslam zihniyetinin oraya yansıdı̆̆g görülüyor..$^{59}$

$\mathrm{Bu}$ ifadede ikona ve çininin ibadete yönelik aynı işlevi gördüğü fikrinden ${ }^{60}$ ziyade sanatsal üslubun, yaklaşımın benzerliği anlamı daha baskındır. Gritchenko'nun seyahatinde Osmanlı'ya dair gördüklerinin sürekli Bizans'ı andırmasının abartılı bir örneği olarak ikona ve çini arasındaki devamlılık gösterilebilir. Müzik ve ibadet de Gritchenko için bu paralellikleri kurmanın bir aracına dönüşür. Mevlevihane ziyareti sırasındaki gözlemi, ayinin bütünüyle Bizans kültürünün ürünü olduğu kanısında olduğunu gösterir.

[B]ütün bu merasimde [ayinde] Bizans'tan, onun kurallarından, müziğinden, ritminden, esrimesinden ve mistik dönüşümünden, insana ve onun ilahi kişiliğine yönelik saygının fark edildiği selamlardan alınmış o kadar çok şey var ki... ${ }^{61}$

İbadetin tarihsel sürekliliğini, bedenin çalıştırılması konusunda daha da geriye itip, Antik Yunan'dan başlayan bir yöntemin Bizans'ta ve Osmanlı'da devam ettiğini düşünür. "[Muhammed Peygamber] [d]insel ibadeti insan bedenini çalıştırmakla birleştirmişti. Bu zaten eski Yunanlarda, Bizanslilarda da cereyan etti. ${ }^{.62}$

\section{Paralel Travmalar}

Gritchenko, kültürün ve ibadetin sürekliliği—ya da aslında tarihdışılığı—fikrini Bizans tarihinin iki kanlı olayının da bir şekilde Osmanlı'da tekrarını görmekle devam ettirir. Şehrin sakinleri için travmatik ve şehrin dönüşümünde önemli yeri olan bu iki tarihsel olay Nika İsyanı (532) ve Dördüncü Haçılı Seferidir (1204). Gritchenko Nika İsyanı'nın katliamla bastırılmasını II. Mahmud'un Yeniçerilerin tasfiyesi sürecinde aynı bölgede, yani Hippodrom/Atmeydanı'nda katledilmesini benzer olaylar olarak sunar:

59 Gritchenko, Günlük, 145.

60 Tarkan Okçuoğlu, Gritchenko'nun ikona ve çini arasında işlevsel bir analoji kurmuş olabileceğini örnekler, bkz. Tarkan Okçuoğlu ve Emir Alışık, "Alexis Gritchenko: İstanbul Mavi ve Pembe," 8 Kasım 2020 Meşher Podcast adlı podcast içinde, haz. Karoly Aliotti, Şeyda Çetin ve Ebru Esra Satıcı, 17:45, https://open.spotify.com/episo de/5genRTToiPvMjVc781wKVw?si=0kkYqJnRSKOst5b4g-BABA

61 Gritchenko, Günlük, 167.

62 Gritchenko, Günlük, 103. 
Çileden çıkmış kalabalıklar [Maviler ve Yeşiller] imparatorluk alametlerini yeni bir imparatora teslim etmek üzereyken, Theodora pek cesur sayılamayacak eşinin [İoustinianos'un] canını ve tahtını kurtarmış, bu arada da Belisarios Hipodrom'a kapatılmış beş yüz bin Yeşil'i yok etmişti.

Osmanlı döneminde de bu meydanda bir başka trajedi yaşanmış ve II. Mahmud birkaç gün içinde binlerce yeniçeriyi katlettirmişti. ${ }^{63}$

Gritchenko burada, kurumların, aktörlerin ve nihayet zamanın farklılığını geri plana iterek, mekânı birleştirici, adeta bir sabit olarak belirler ve bunu yaparken mekânı da tarihdışına iter.

Gritchenko, “[g]ünümüz Avrupası Türklerle ilişkilerinde, Haçlıların Bizans’a karşı izledikleri politikayı benimsiyor" yorumunda muhtemelen Dördüncü Haçlı Seferi’ni kastediyor olmalı, çünkü bu beyanın hemen öncesinde "[h]açlıların torunlarının kültürde ilerledikleri kesin ama alışkanlıkları değişmemiş. İyi savunulmamış şeyi ele geçirip sahiplenmek için ne yapmak gerektiğini biliyorlar!” şeklindeki ilanı, akla Dördüncü Haçlı Seferi’nde yapılan yağmayı getiriyor. ${ }^{64}$ Gritchenko bu sefere de günlüğünde uzunca yer verir ve tıpk1 1453'ü anlattığ 1 kısımda olduğu gibi burada da bir kronik yazarına başvurur: Geoffrey Villehardouin. ${ }^{65} \mathrm{Bu}$ alıntıda Haçlılar'la İstanbul'daki işgal kuvvetlerinin, Bizans ile de Osmanlı'nın eşleştirilmesi, 800 seneye yayılan bitmek bilmez bir Doğu Batı savaşı fikri taşıması açısından ilginçtir ama Gritchenko'nun bu genellemeleri, bu kümeleri hangi parametrelere göre belirlediği muğlaktır.

Gritchenko'nun kurduğu tüm bu paralelliklerin yüzeysel olduğunu ve ressamın otantik Bizans hissiyatını yaşadı ̆̆ını gösterme çabası içinde olduğunu belirtmekte fayda var. Bizans tarihi hakkında güncel yazını yakından takip eden ${ }^{66}$ ressamın içinde yaşadığı İstanbul'la, Bizans Konstantinopolis'i arasında bu tip bağlantılar ve paralellikler kurması, görünürde, Günlük'ün akademik bir amaç gütmeyen doğasından kaynaklanır. Kitabın barındırdığı bu çelişkiye Gritchenko şöyle değinir:

Konstantinopolis hakkında üç tür kitap yazılabilir: 1) Tamamen bilimsel, arkeolojik araştırmalar; 2) Derlemeler ve 3) Kişisel eserler. Ben bu sonuncu türü tercih ettim. Konstantinopolis hakkında az sayıda bilimsel araştırma mevcuttur. Çeşitli dillerde kaleme alınan derlemelerin sayısı ise az değildir, ancak kişisel kitaplar da en az bilimsel eserler kadar nadirdir. [...] Konstantinopolis'in (deyim yerindeyse) fizyolojisi, bir ressamın gözünden izlenen ve evrene ilişkin şahsi bir anlayışla aydınlatılan anıtların hayatıdır, sokaklardır, dünyanın 1şıltılı ve sanatsal yüzüdür; işte, benim kitabımın temel ilkesi bu. Planı, amacı ve varlık nedeni bu. $B u$ kitapta, Ayasofya'nın 537 yılında inşa edilmiş olması ikincil bir öneme sahip; asıl önemli olan, onun sanatsal etkisi, sanatçının zihninde ve ruhunda bıraktığı izdir. ${ }^{67}$

63 Gritchenko, Günlük, 81.

64 Konuyla ilgili güncel bazı kaynaklar için bkz. Alfred Andrea, Contemporary Sources for the Fourth Crusade Leiden: Brill, 2000); Michael J. Angold, The Fourth Crusade: Event and Context (New York: Routledge, 2014); Thomas F. Madden, "The Venetian Version of the Fourth Crusade: Memory and the Conquest of Constantinople in Medieval Venice," Speculum 87, no. 2 (2012): 311-344.

65 Gritchenko, Günlük, 233, 234.

66 Charles Diehl'in 1919'da yayımlanan kitabı Byzance. Grandeur et Décadence'1 İstanbul'dayken okuduğunu söyler, bkz. Gritchenko, Günlük, 160.

67 Gritchenko, Günlük, 18. Vurgu makalenin yazarına aittir. 


\section{Binalar ve Tarihyazımı}

Bu noktada, Ayasofya'da spolia kullanımı ya da içerideki atmosferi tarif ederken kullandığı benzetmenin tarihsel kaynaklarında olduğu gibi diğer Bizans yapılarıyla karşılaşmalarına ve bu karşılaşmalarda belirleyici olan ressamın okumalarına dönelim. Gritchenko'nun Khora Manastırı ziyaretleri, Ayasofya'nın peşinden, en sık olanlardır. Bu sıklığın yanında, Khora'nın, ressamın bir şekilde Bizans mozaik ve freskleriyle yoğun olarak karşılaşı ğı bir nokta olduğu için, Bizans sanatını algılayışına dair en fazla yoruma rastladığımız yer olduğu da söylenebilir. Gritchenko, Bizans sanatının durağan ve homojen olduğu yanılgısının Charles Diehl ve Gabriel Millet'nin eserleriyle kırıldığını belirtir. ${ }^{68}$ Girtchenko bu fikri özellikle Millet'nin Daphni Manastırı hakkındaki kitabın $1^{69}$ ve kendi Khora ziyaretini göz önünde bulundurarak destekler. Daphni'nin dokuzuncu yüzyıl $[\text { sic }]^{70}$ mozaikleri ile Theodoros Metokhites döneminde uygulanan Khora'nın on dördüncü yüzyıl mozaiklerini kıyaslayarak Bizans sanatının evrilen bir sanat olduğu sonucuna varır (F.8-9).

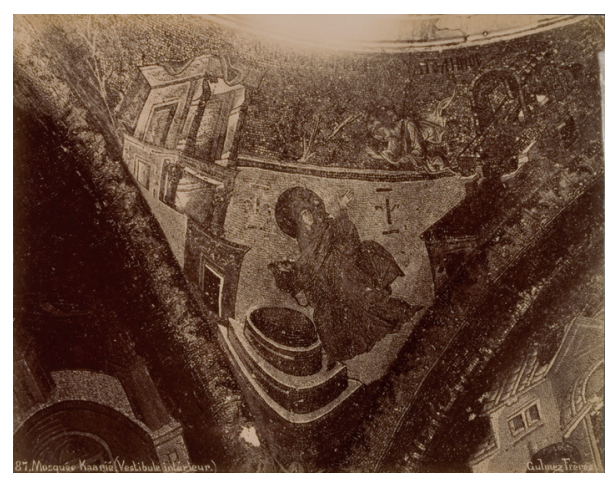

Figür 8: Meryem'e Müjde, diş narteks, Khora. Gülmez Kardeşler. Suna ve İnan Kıraç Vakfi Fotoğraf Koleksiyonu, FKA_001763
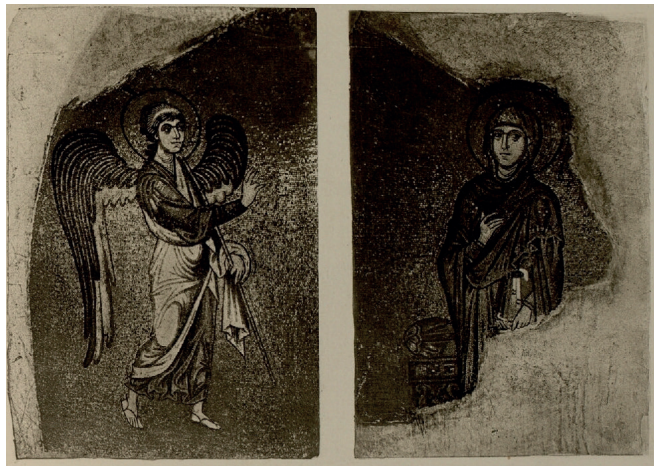

Figür 9: Meryem'e Müjde, Daphni Manastır1, Atina, 12. yüzyıl. (Gabriel Millet, Le Monastère de Daphni: Histoire, architecture, mosaïques. Paris: 1899) https:// bibliotheque-numerique.inha.fr/idurl/1/16240

Gritchenko'nun Khora'daki mozaikleri yakından görmesi fiziksel olarak güçtü, çünkü onun ziyareti esnasında bu mozaiklerin bir kısmının üstü badanalanmıştı, açık olanlar da bakımsız durumdayd1. ${ }^{71} 1876$ 'da yapılan restorasyon sayesinde Gritchenko'nun ziyareti esnasında bazı mozaikler açığa çıkmış durumda olsa da bunların büyük bölümü hâlâ görünür değildi,

68 Gritchenko, Günlük, 170.

69 Gabriel Millet, Le Monastère de Daphni: Histoire, architecture, mosaïques (Paris: Ernest Leroux, 1899)

70 Millet'ye göre manastırda İoustinianos dönemine kadar tarihlenen yapılar olsa da bugün arkeolojik ve yazılı veriler manastırın erken 12. yüzyıla tarihlenmesine yol açmıştır. Tarihlendirmeyle ilgili detaylı bir tartışma için bkz. Charalambos Bouras, "The Daphni Monastic Complex Reconsidered," AETOS: Studies in Honor of Cyril Mango içinde, hazırlayan Ihor Ševčenko ve Irmgard Hutter (Stuttgart: B. G. Teubner, 1998), 1-15.

71 Gritchenko, Günlük, 168 
görünür olanlarsa iyi durumda değildi. ${ }^{72}$ Gritchenko'nun bu mozaikleri incelemesine olanak tanıyan, İstanbul Rus Arkeoloji Enstitüsü başkanı Fyodor Uspenski’nin 1899-1904 arasında Khora'da gerçekleştirdiği dokümantasyon ${ }^{73}$ ve bulgularının 1906 'da enstitü bülteninin on birinci sayısında ${ }^{74}$ yayımlanmasıdır. Gritchenko'nun görme şansı elde ettiğini söylediği bu albümse çok kapsamlı bir şekilde tüm mozaiklerin fotoğraflarını içerir. Hem yapının içinde gözlediği hem de Uspenski yönetiminde hazırlanan albüm sayesinde haberdar olduğu mozaikler Gritchenko’ya Bizans sanatının geçirdiği dönüşümü göstermenin yanında, ressamı erken İtalyan Rönesansı ile kıyaslama yapmaya iter. ${ }^{75}$ Giotto (yak. 1267-1337), Cimabue (yak. 1240-1302), Duccio (yak. 1255-1319) gibi ressamların üretimleri ile Khora'da karşılaştığı Bizans sanatı arasında benzerlikler görür ve bu ikisinin birbiriyle yarıştığını düşünür. Erken Rönesans sanatçılarının Bizans'la ilişkileri ister etkilenme ister kopuş bağlamında olsun sanat tarihyazımında Vasari' den beri gözlenir, yirminci yüzyılın tarihyazımı bu ilişkilerin giriftliğini sıklıkla konu edinir. ${ }^{76}$ Bunun yanında, Gritchenko'nun İstanbul'u ziyaret ettiği dönemde, Bizans sanatının post empresyonist resme yakın olduğu düşünülüyor ${ }^{77}$ ve bu yakınlık övgüyle tespit ediliyordu. Henry Maguire, Clive Bell'in 1914'te, post empresyonizmin Bizans sanatiyla “el sıkıştı̆̆ını” yazdığını aktarır. ${ }^{78}$ Sonuç olarak, Gritchenko’nun Khora gözlemlerini İtalyan Erken Rönesansı ile birlikte düşünmesi hem döneminin düşüncesiyle uyum içindedir hem de sanat tarihi bağlamında yersiz değildir. Ayrıca, Khora, ressamın bir Bizans mozaiğinin etüdünü yaptığı yer olmasıyla da bu seyahatte önemli yer tutar (F.10). Gritchenko'nun İstanbul dönemi resimlerinde pek çok Bizans mimari eserini hem manzaralarda hem de iç mekân resimlerinde görüyoruz. Bu dönemde üretilen bir resim doğrudan Khora' daki bir mozaiğin ikonografisini

72 "To be sure, nineteenth and early-twentieth-century visitors knew the building as the Mosaic Mosque. Its decorations were never entirely covered; many of the vault mosaics remained visible although dulled by accumulated layers of dirt and grime." [Elbette, on dokuzuncu ve erken yirminci yüzyıl ziyaretçileri yapıyı Mozaik Camii olarak tanıyordu. Süslemeleri hiçbir zaman tamamen kapatılmamış, biriken kir ve pislikle canlılıkları yitse de tavan mozaiklerinin birçoğu görünür vaziyetteydi] Bkz. Robert G. Ousterhout, "(Re) Presenting the Kariye Camii: Architecture, Archaeology, and Restoration," Restoring Byzantium: The Kariye Camii in Istanbul (Chora Church) içinde, haz. Holger A. Klein ve Robert G. Ousterhout (New York: Miriam and Ira D. Wallach Art Gallery, Columbia University in the City of New York, 2004), 32.

73 Üre, "Byzantine Heritage, Archaeology, and Politics between Russia and the Ottoman Empire," 206.

74 Izvestiia Russkogo Arkheologicheskogo Instituta v Konstantinopole (IRAIK) [İstanbul Rus Arkeoloji Enstitüsü Bülteni] 11 (1906).

75 Gritchenko, Günlük, 174.

76 Bkz. Ernst Kitzinger, The Byzantine Contribution to Western Art of the Twelfth and Thirteenth Centuries, Dumbarton Oaks Papers 20 (1966): 25-47; Hans Belting, Likeness and Presence: A History of the Image before the Era of Art, çev. Edmund Jephcott (Chicago: The University of Chicago Press, 1997), özellikle In the Greek Manner bölümü; Angeliki Lymberopoulou ve Rembrandt Duits, haz., Byzantine Art and Renaissance Europe (New York: Routledge, 2013), özellikle Hans Bloemsma, "Byzantine Art and Early Renaissance Painting," 37-61.

77 J. B. Bullen, "Byzantinism and Modernism 1900-14”, The Burlington Magazine 141, no: 1160 (Kasim 1999): $669-670$.

78 Henry Maguire, "Truth and Convention in Byzantine Descriptions of Works of Art," Dumbarton Oaks Papers 28 (1974), 113. Ayrıca modern sanat ile Bizans sanatı arasındaki diyalektik ilişki için bkz. Robert S. Nelson, "Modernism's Byzantium Byzantium's Modernism," Byzantium/Modernism: The Byzantine as Method in Modernity içinde, haz. Roland Betancourt ve Maria Taroutina (Leiden: Brill, 2015), 15-37. 
kullanır. Bu resim Meşher'deki sergide Kariye Camii'nde Bir Mozaik Detayı (F.11) olarak anılıp Haziran 1920'ye tarihlenir, ancak resim açıkça, Khora'nın iç narteksinde bulunan Ísa, Havari Petros'un Kayınvalidesini Iyileştiriyor mozaiğinin bir çeşitlemesidir. Figürlerin konumlanışı ve renklerin tekrarı (özellikle İsa’nın kostümünün ve kayınvalidenin yastığının rengi) bu ilişkiyi gözler önüne serer. Gritchenko'nun, kendisiyle aynı esnada İstanbul'da bulunan Thomas Whittemore'la görüştüğü ve ona 66 adet resim sattığ biliniyor, ${ }^{79}$ fakat satılan eserlerin akıbeti şimdilik bilinmemektedir. ${ }^{80}$ Whittemore'a satılan resimlerin büyük kısmının şehrin Bizans eserleriyle bağlantılı olması yüksek olasılıktır, dolayısıyla Khora'daki mozaiğin etüdünün Gritchenko'nun tek seferlik bir denemesi olmadığ olduğu düşünülebilir.

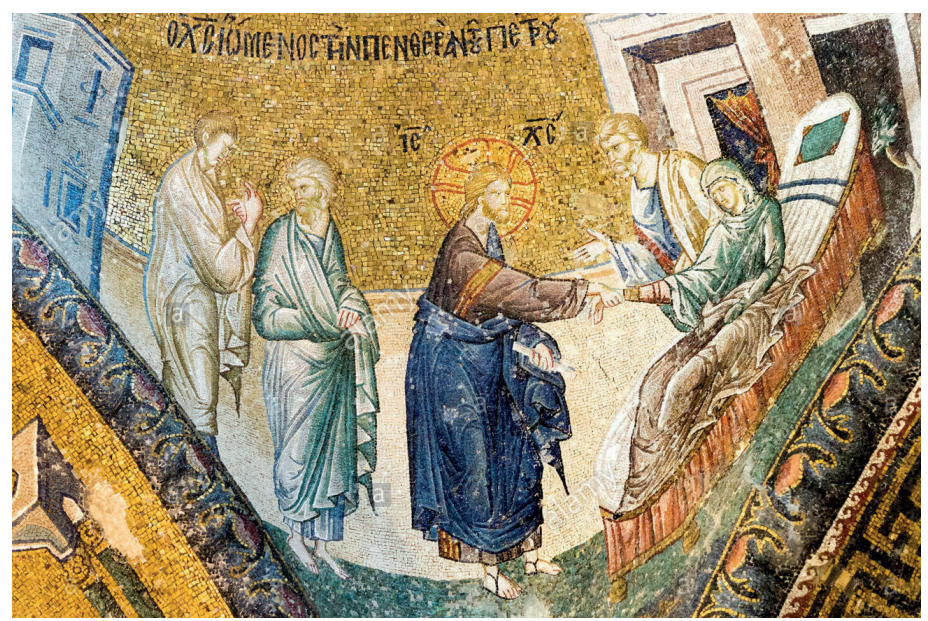

Figür 10: İsa, Havari Petros'un Kayınvalidesini İyileştiriyor, iç narteks, Khora. Erişim tarihi: 24.10.2020 (https://www.choramuseum.com/history/mosaics-and-frescoes/) 


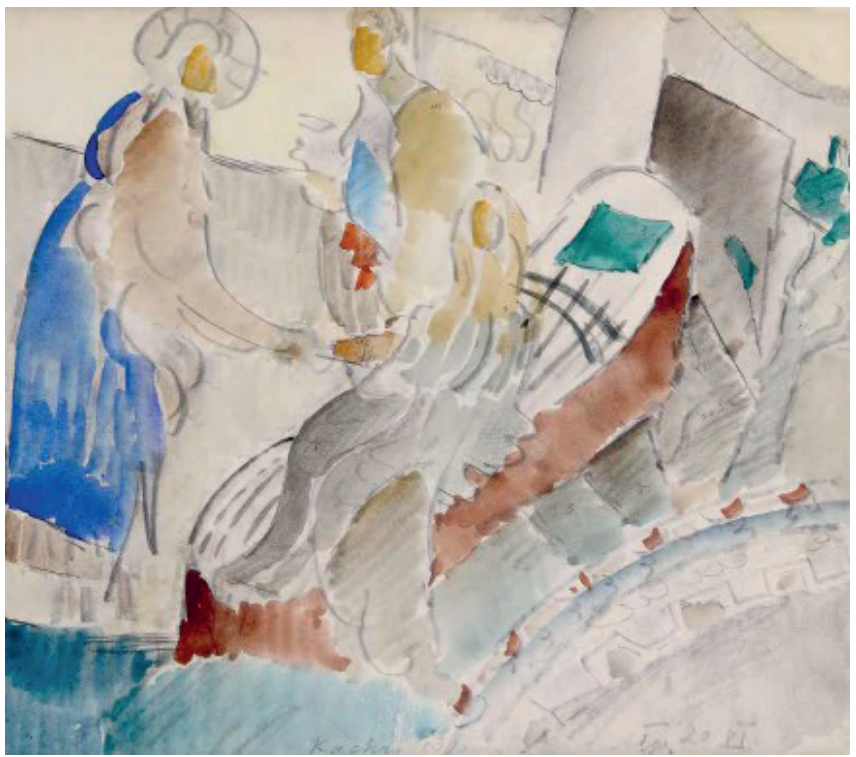

Figür 11: Alexis Gritchenko, Kariye Camii'nde Bir Mozaik Detay1, Haziran 1920, Gizella Lopusanszky ve Alexander Demko Koleksiyonu, ABD.

(Alexis Gritchenko: İstanbul Yılları, Meşher, 2020)

Son olarak da Gritchenko’nun Bizans yapılarını ziyaretleri esnasında düştüğü bazı tarihsel yanılgılara değinmek gerekir. Bunların izlerini takip etmek mümkündür, yani ressam kimi zaman okudukları kimi zaman da muhtemelen şehirde duydukları dolayısıyla, günümüzde güncellenmiş bazı eski bilgileri tekrar eder. Bunların belki, yanlışlığın derecesi bakımından, en çarpıcı olanı 1572 tarihli Mimar Sinan eseri olan Kadırga Sokullu Mehmed Paşa Camii'nin, muhtemelen beşinci yüzyılın başında inşa edilen Aya Anastasia Kilisesi'nden ${ }^{81}$ devşirilerek cami yapıldığını anlattığg kısımdır. ${ }^{82}$ Tarkan Okçuoğlu, bu tip yanlışların şehrin sözlü kültüründe dolaşan bilgilerden kaynaklanıyor olabileceğini öne sürer. ${ }^{83}$ Atik Mustafa Paşa Camii'nin, beşinci yüzyıl yapısı Aziz Petros ve Markos’tan devşirildiği bilgisi de ${ }^{84}$ eskidir ve artık bu yapının dokuzuncu yüzyıla tarihlenen Azize Thekla kilisesi olduğu bilgisi Günlük'ün Türkçe edisyonunda çevirenin notu olarak paylaş1lır. ${ }^{85}$ Ressam, 5 Ağustos 1920'de ziyaret ettiğini söylediği Gül Camii’nin dokuzuncu yüzyıl yapısı Aya Theodosia'dan devşirildiği bilgisini

81 Raymond Janin, La Géographie Ecclésiastique de L'empire Byzantin, Vol. 1, Le Siège de Constantinople et Le Patriarcat Oecuménique, Pt. 3, Les Églises et Les Monastères. İkinci basım (Paris: Institut français d'études byzantines, 1969). 22-25.

82 Gritchenko, Günlük, 133.

83 Tarkan Okçuoğlu ve Emir Alışık, “Alexis Gritchenko: İstanbul Mavi ve Pembe,” 8 Kasım 2020 Meşher Podcast adlı podcast içinde, haz. Karoly Aliotti, Şeyda Çetin ve Ebru Esra Satıc1, 34:00, https://open.spotify.com/episo de/5genRTToiPvMjVc781wKVw?si=0kkYqJnRSKOst5b4g-BABA.

84 Gritchenko, Günlük, 232.

85 Gritchenko, Günlük, 232. 
aktarır. Bu bilgi Gritchenko'nun seyahat ettiği yıllarda geçerliydi ${ }^{86}$ ancak bugün yapının on ikinci yüzyıla tarihlenen bir Komnenos hanedanı manastırı olan İsa Euergetes olduğu düşünülmektedir. ${ }^{87} 1920$ Nisan'ında Topkapı Sarayı alanında gezerken Gotlar Sütunu ile karşılaşan Gritchenko, sütunun üzerindeki Latince yazıtı okur ve eskiden bu sütunun üzerinde kimin heykeli olduğunu söyler: ${ }^{88}$ ona göre sütunun kaidesinde Fortuna reduci ob devietos Gothos yazar ve sütun eskiden Byzantion kentinin efsanevi kurucusu Byzas'in heykelini taşımıştır. Öncelikle, ressam yazıtı hatalı aktarır, bu yazım hatası yazıtın içinde olduğu koşuldan kaynaklanmış olabilir, doğru yazım şu şekildedir; Fortunae reduci ob devictos Gothos $^{89}$ ve yazıtın da ima ettiği gibi Fortuna'ya (Tykhe) yapılan bir adaktır. Altıncı yüzyıldan Bizanslı yazar Lidyalı İoannes bu sütunun üzerinde Fortuna heykeli olduğunu aktarır. ${ }^{90} \mathrm{Bu}$ örneklerde görüldüğü gibi Gritchenko, kendi döneminin tarihyazımı ve belki sözlü kültüründen bolca faydalanmıştı ve bilgilerinin bir kısmı günceldi.

\section{Sonuç}

Gritchenko'nun Günlük'ü, iyi çalışılmış bir tarihsel fantezidir. Ressamın tarihyazımını takibinin ve kullanımının yoğunluğu, yapılarla ilgili aktardığı bilgileri, çağdaşı okuyucu için güncel kılmakla birlikte, bugün onun kaynak olarak kullanılmasına yeterli değildir. Spolia malzeme kullanımına gösterdiği dikkat, binaların eski ve yeni hallerini kıyaslamaları, kurgusunu inandırıcı kılan etkileyici unsurlardır. Yine de Gritchenko'nun Günlük'te kurguladığı, Eski Köprü’den geçerek vardığı Tarihi Yarımada, içinde barındırdığı mekanlar, yapılar, insanlar, o insanların gündelik hayatlarıyla birlikte tarihin akışının dışında kalmış, ancak tüm parçalarının birbiriyle uyum içindeki fantastik atmosferiyle bir hierotopos'tur. ${ }^{91}$ Günlük'te,

86 Örneğin bkz. Alexander Van Millingen, Byzantine Churches in Constantinople: Their History and Architecture (Londra: Macmillen and Co., 1912), 164, 335.

87 Örneğin bkz. Paul Magdalino, Ortaçağda İstanbul: Altıncı ve On Üçüncü Yüzyıllar Arasında Konstantinopolis 'in Kentsel Gelişimi (İstanbul: Koç Üniversitesi Yayınları, 2012), 7, 85, 88.

88 Gritchenko, Günlük, 92.

89 Lat. Gotların mağlup edilişiyle döndürülen Fortuna'ya. Bkz. Cyril Mango, "The Triumphal Way of Constantinople and the Golden Gate," Dumbarton Oaks Papers 54 (2000): 177.

90 Mango, "The Triumphal Way," 177.

91 Hierotopy terimi, esasında ortaçağ kutsal mekânlarına yaklaşıken, kutsal mekânın tüm parçalarını ve ritüeller, söylem gibi soyut unsurların da hesaba katılarak bütünsel bir insan kurgusu olarak ele alınması düşüncesiyle ortaya atılmı̧̧ır. Lidov en basit haliyle terimi şöyle açıklar: "Hierotopy is creation of sacred spaces regarded as a special form of creativity, and a field of historical research which reveals and analyses the particular examples of that creativity." [Hierotopy, özel bir yaratım tipi olarak kutsal alan yaratımı ve bu yaratımın örneklerini ortaya çıkarıp analiz eden tarihsel çalışma alanıdır]. Terimin ortaya atılışı için bkz. Alexei Lidov, "Hierotopy: The Creation of Sacred Spaces as A Form of Creativity and subject of Cultural History," Hierotopy: Creation of Sacred Spaces in Byzantium and Medieval Russia içinde, haz. Alexei Lidov (Moskova: Progress-Tradition, 2003), 32-58. Ancak Lidov, daha sonra hierotopy yaklaşımının ortaçağ kutsal mekânıyla sınırlandırılamayacağını ifade eder: "It is noteworthy, that Byzantine "spatial icons", mostly unusual in modern European context, have a typological parallel in the contemporary art of performances and multi-media installations, which have nothing to do with the Byzantine tradition from a historic or symbolic point of view. What they share is a basic principle of absence of a single source of images, while the imagery is created in space by dynamically changing forms and the beholder actively participates in the re-creation of the spatial imagery. Such an aspect shows how far 
kutsal mekânın tanımını Ortodoks Hristiyanlığı veya İslam tanrısının varlığıyla yapmaz ressam. Orada Gritchenko, "çok gerilerde kalmış çağların canlı atmosferi” diye adlandırdığı, tarihin dışında kalmış — bu şekliyle de aşkın—1şı oyunları, mekânları, insanlarının kılıkları ve sesleri ve tüm diğer duyumsallıklarla performatif bir kutsal mekândadır. Günlük bu yönleriyle askerî işgal altındaki bir şehrin çok sert gerçekliğini dışlayan başka bir alan yaratır, bu alan, Gritchenko'nun sıklıkla ifade ettiği gibi şehrin mabetlerinin avlularına sığınmasını çağrıştıran, arzulanan bir alandir.

Yine de Günlük’te, yazarın seyahatinin özellikle ilk zamanlarındaki sefaleti ve açlığı, Osmanlı sanatı ve yapıları üzerine-Bizans'la ilgili kısımlar kadar hacimli olmasa da—gözlem ve analizleri de araştırmaya değer konulardır. ${ }^{92}$ Gritchenko'nun Osmanlı'nın güncel sanatı ve akademi ressamları ile olan ilişkileri hem ressamın sanat anlayışını açıklar hem de Osmanlı modern resim tarihi için değerli veriler sunar. ${ }^{93}$

Gritchenko'nun İstanbul seyahatinin ardından, Paris'e yerleşmeden önce Thomas Whittemore'un desteğiyle gerçekleştirdiği Yunanistan seyahati de hem bu seyahatiyle ilgili olası anlatıları ve sanatsal üretimiyle ilgi çekici konulardır. Yunanistan seyahatinde ürettiği resimlerin bir kısmının Bizans yapılarını konu aldığı düşünülürse, İstanbul ve Yunanistan’da ürettiği Bizans'a dair eserler başlı başına bir araştırma hatta sergi konusu olabilir. Hem bu olası sergi hem de Thomas Whittemore'a sattığı ve şu an kayıp olan 66 resmin bulunma ihtimali yirminci yüzyıl başı modernist Bizantinizm resmi konusunda heyecan vericidir.

we can go in our analysis of the hierotopical approach.” [Modern Avrupa bağlamında alışılmadık olan Bizans "mekânsal ikonalarının", sembolik veya tarihsel olarak Bizans geleneği hiç ilgisi olmayan çağdaş performans sanatları ve multimedya enstalasyonları ile tipolojik benzerlikleri olması dikkate değerdir. Tahayyülün, durmaksızın devinen formlarla mekânsal tahayyülün yeniden üretiminde aktif rol alan izleyici tarafindan mekânda üretilmesi gibi, bunların (Bizans geleneği ile çağdaş performans sanatları ve multimedya enstalasyonlarının) ortak noktası, imgelerin tekil kaynağının olmaması temel prensibidir. Böylesi bir boyut hierotopy yaklaşımının analizi ile ne kadar ileri gidebileceğimizi gösterir]. Bkz. Alexei Lidov, "Creating the Sacred Space: Hierotopy as A New Field of Cultural History," Spazi e percorsi sacri. I santuari, le vie, i corpi (2014): 78.

92 Tarkan Okçuoğlu ve Emir Alışık, "Alexis Gritchenko: İstanbul Mavi ve Pembe," 8 Kasım 2020 Meşher Podcast adlı podcast içinde, haz. Karoly Aliotti, Şeyda Çetin ve Ebru Esra Satıcı, 34:00, https://open.spotify.com/episo de/5genRTToiPvMjVc781wKVw?si=0kkYqJnRSKOst5b4g-BABA.

93 Örneğin bkz. Ayşenur Güler, “Alexis Gritchenko'nun İstanbul Yıllarının İzinde," Alexis Gritchenko: İstanbul Ylllarl içinde, haz. Nilüfer Şaşmazer (İstanbul: Vehbi Koç Vakfi, 2020), 131-204; Güler, "Tale of an Émigré Artist in Istanbul: The Impact of Alexis Gritchenko on the 1914 Generation of Turkish Artists," Transcending the Borders of Countries, Languages, and Disciplines in Russian Émigré Culture içinde, haz. Christoph Flamm, Rolan Marti ve Ada Raev (Newcastle: Cambridge Scholars Publishing: 2018): 119-143. 
Teşekkür: Bu makaledeki gözlem ve argümanların bir kısmı, daha önce Meşher'in Alexis Gritchenko: Istanbul Yıllarl adıyla 2020'de düzenlediği sergi kapsamında yayınlanan Meşher Podcast programının, 8 Kasım 2020'de Tarkan Okçuoğlu ile birlikte konuğu olduğum Alexis Gritchenko: İstanbul Mavi ve Pembe bölümünde tartış1lmıştır. Tüm Meşher ekibine, özellikle de serginin küratörleri Ebru Esra Satıcı ve Şeyma Çetin'e, Karoly Aliotti'ye ve Nazlı Efsa Aktar'a beni konuk ettikleri için teşekkür ederim. Tarkan Okçuoğlu'na, beni Alexis Gritchenko'nun eserleri ve günlüğü üzerine düşünmeye davet ettiği ve bahsi geçen programın hazırlanışı esnasındaki zihin açıcı fikir paylaşımları nedeniyle minnettarım.

Hakem Değerlendirmesi: Dış bağımsız.

Çıkar Çatışması: Yazar çıkar çatışması bildirmemiştir.

Finansal Destek: Yazar bu çalışma için finansal destek almadığını beyan etmiş̧ir.

Peer-review: Externally peer-reviewed.

Conflict of Interest: The author has no conflict of interest to declare.

Grant Support: The author declared that this study has received no financial support.

\section{Kaynakça/References}

Alshanskaya, Alena et al., hazırlayan. Imagining Byzantium Perceptions, Patterns, Problems. Mainz: Verlag des Römisch-Germanischen Zentralmuseums, 2018.

Andrea, Alfred. Contemporary Sources for the Fourth Crusade. Leiden: Brill, 2000.

Angold, Michael J. The Fourth Crusade: Event and Context. New York: Routledge, 2014.

Auzépy, Marie-France, hazırlayan. Byzance En Europe. Saint-Denis: Presses Universitaires Vincennes, 2003.

Beck, James. "Piero della Francesca at San Francesco in Arezzo: An Art-Historical Peregrination." Artibus et Historiae 24, no. 47 (2003): 51-80.

Belting, Hans. Likeness and Presence: A History of the Image before the Era of Art. Çeviren Edmund Jephcott. Chicago: The University of Chicago Press, 1997.

Betancourt, Roland ve Maria Taroutina, hazırlayan. Byzantium/Modernism: The Byzantine as Method in Modernity. Leiden: Brill, 2015.

Bouras, Charalambos. "The Daphni Monastic Complex Reconsidered." AETOS: Studies in Honor of Cyril Mango içinde. Hazırlayan Ihor Ševčenko ve Irmgard Hutter. Stuttgart: B. G. Teubner, 1998, 1-15.

Buchanan, Ian. "Historicism." A Dictionary of Critical Theory içinde. Oxford University Press, 2018. Erişim tarihi 29.04.2021. https://www.oxfordreference.com/view/10.1093/acref/9780198794790.001.0001/acref9780198794790-e-323.

Bullen, J. B. "Byzantinism and Modernism 1900-14". The Burlington Magazine 141, no: 1160 (Kasım 1999): $665-675$.

Carr, Annemarie Weyl. "Matthew." The Oxford Dictionary of Byzantium (Oxford: Oxford University Press, 1991). Erişim tarihi 03.02.2021 https://www.oxfordreference.com/view/10.1093/acref/9780195046526.001.0001/ acref-9780195046526-e-3390.

. "Orans." The Oxford Dictionary of Byzantium içinde. Oxford: Oxford University Press, 1991. Erişim tarihi 03.02.2021, https://www.oxfordreference.com/view/10.1093/acref/9780195046526.001.0001/acref9780195046526-e-3962.

Dethier, P. A. ve C. Hopf, hazırlayan. Monumenta Hungariae Historica. Ser. Scriptures (Masodik osztaly Irok). C. 22.1. Galata/Pera ya da Budapeşte: 1872 ? ya da 1875 ?

Diehl, Charles. Byzance: Grandeur et décadence. Paris: E. Flammarion, 1919. 
Doukas. Historia Turco-Byzantina. Hazırlayan Harry J. Magoulias. Detroit: Wayne State University Press, 1974. Gautier, Theophile. Constantinople of To-day. Çeviren Robert Howe Gould. Londra: David Bogue, 1854. Gritchenko, Alexis. Deux ans à Constantinople. Paris: Quatre Vents, 1930. Ístanbul'da İki Yıl 1919-1921: Bir Ressamın Günlüğ̈̈, çeviren Ali Berktay. İstanbul: Yapı Kredi Yayınları, 2020.

- O sviaziakh russkoi zhivopisi s Vizantiei i Zapadom XIII-XX vv: Mysli zhivopistsa [Rus Resminin Bizans ve Batı ile İlişkisi, 13.-20. Yüzyıllar: Ressamın Görüşleri]. Moskova: 1913.

Güler, Ayşenur. "Tale of an Émigré Artist in Istanbul: The Impact of Alexis Gritchenko on the 1914 Generation of Turkish Artists." Transcending the Borders of Countries, Languages, and Disciplines in Russian Émigré Culture içinde. Hazırlayan Christoph Flamm, Rolan Marti ve Ada Raev. Newcastle: Cambridge Scholars Publishing: 2018. 119-143.

. “Alexis Gritchenko’nun İstanbul Yıllarının İzinde.” Alexis Gritchenko: İstanbul Yılları içinde. Hazırlayan Nilüfer Şaşmazer. İstanbul: Vehbi Koç Vakfı, 2020. 131-204.

Izvestiia Russkogo Arkheologicheskogo Instituta v Konstantinopole (IRAIK) [İstanbul Rus Arkeoloji Enstitüsü Bülteni] 11 (1906).

Janin, Raymond La Géographie Ecclésiastique de L'empire Byzantin, Vol. 1, Le Siège de Constantinople et Le Patriarcat Oecuménique, Pt. 3, Les Églises et Les Monastères. İkinci basım. Paris: Institut français d'études byzantines, 1969.

Kandinsky, Wassily. Concerning the Spiritual in Art. Çeviren Michael Sadleir ve Francis Golffing. New York: Wittenborn, Schultz, 1947.

Kazhdan, Alexander, hazırlayan. The Oxford Dictionary of Byzantium. Oxford: Oxford University Press, 1991.

Kitzinger, Ernst. "The Byzantine Contribution to Western Art of the Twelfth and Thirteenth Centuries." Dumbarton Oaks Papers 20 (1966): 25-47.

“Laurentian Codex,” 1377. F.p.IV.2. National Library of Russia, St. Petersburg.

Lidov, Alexei. "Hierotopy: The Creation of Sacred Spaces as A Form of Creativity and subject of Cultural History." Hierotopy: Creation of Sacred Spaces in Byzantium and Medieval Russia içinde. Hazırlayan Alexei Lidov. Moskova: Progress-Tradition, 2003. 32-58.

"Creating the Sacred Space: Hierotopy as A New Field of Cultural History." Spazi e percorsi sacri. I santuari, le vie, i corpi (2014): 61-89.

Lymberopoulou, Angeliki ve Rembrandt Duits, hazırlayan. Byzantine Art and Renaissance Europe. New York: Routledge, 2013.

Mabeyinci Pavlos. Ayasofya'nın Betimi. Çeviren Samih Rifat. İstanbul: İstanbul Araştırmaları Enstitüsü Yayınlar1, 2010.

Madden, Thomas F. "The Venetian Version of the Fourth Crusade: Memory and the Conquest of Constantinople in Medieval Venice." Speculum 87, no. 2 (2012): 311-344.

Magdalino, Paul. Ortaçağda İstanbul: Altıncı ve On Üçüncü Yüzyıllar Arasında Konstantinopolis’in Kentsel Gelişimi. İstanbul: Koç Üniversitesi Yayınları, 2012.

Maguire, Henry. "Truth and Convention in Byzantine Descriptions of Works of Art." Dumbarton Oaks Papers 28 (1974): 111+113-140.

Mango, Cyril. “The Triumphal Way of Constantinople and the Golden Gate.” Dumbarton Oaks Papers 54 (2000): 173-188. 
Marciniak, Przemysław ve Dion C. Smythe, hazırlayan. The Reception of Byzantium in European Culture since 1500. New York: Routledge, 2015.

Matthews, David. Medievalism: A Critical History. Cambridge: D.S. Brewer, 2015.

Meyendorff, John, "Eastern Orthodoxy." Encyclopedia Britannica, erişim tarihi 31 Ocak 2020. https://www. britannica.com/topic/Eastern-Orthodoxy.

Millet, Gabriel. Le Monastère de Daphni: Histoire, architecture, mosä̈ques. Paris: Ernest Leroux, 1899.

Millingen, Alexander Van. Byzantine Churches in Constantinople: Their History and Architecture. Londra: Macmillen and Co., 1912.

Necipoğlu, Gülru. Age of Sinan: Architectural Culture in the Ottoman Empire. Chicago: The University of Chicago Press, 2005.

Nelson, Robert S. “Modernism's Byzantium Byzantium's Modernism.” Byzantium/Modernism: The Byzantine as Method in Modernity içinde. Hazırlayan Roland Betancourt ve Maria Taroutina. Leiden: Brill, 2015. $15-37$.

Okçuoğlu, Tarkan ve Emir Alışık. "Alexis Gritchenko: İstanbul Mavi ve Pembe.” Meşher Podcast adlı podcast içinde. Hazırlayan Karoly Aliotti, Şeyda Çetin ve Ebru Esra Satıc1. https://open.spotify.com/episode/5ge nRTToiPvMjVc781wKVw?si=0kkYqJnRSKOst5b4g-BABA

Ousterhout, Robert G. "(Re) Presenting the Kariye Camii: Architecture, Archaeology, and Restoration." Restoring Byzantium: The Kariye Camii in Istanbul (Chora Church) içinde. New York: Miriam and Ira D. Wallach Art Gallery, Columbia University in the City of New York, 2004. 32-43.

Philippides, Marios ve Walter K. Hanak. The Siege and Fall of Constantinople in 1453: Historiography, Topography, and Military Studies. Farnham: Ashgate, 2011.

Pitarakis, Brigitte ve Olivier Delouis, hazırlayan, henüz yayımlanmamış. Discovering Byzantium in Istanbul: Scholars, Institutions, and Challenges, 1800-1955. İstanbul: İstanbul Araştırmaları Enstitüsü Yayınları, 2021.

Русская летопись с Воскресенского списка [Voskresenkaya’dan Rus Kroniği], list. SPb., 1793-1794. Ch. 1-2; PSRL. SPb., 1856-1859. T. 7-8.

Susak, Vita. “Alexis Gritchenko: Selam Sana İstanbul!” Alexis Gritchenko: İstanbul Yılları içinde. Hazırlayan Nilüfer Şaşmazer. İstanbul: Vehbi Koç Vakfı, 2020. 35-68.

Şaşmazer, Nilüfer, hazırlayan. Alexis Gritchenko: Istanbul Yılları. İstanbul: Vehbi Koç Vakfı, 2020

Tanman, M. Baha ve K. Mehmet Kentel. “Alexis Gritchenko: İşgal Dönemi İstanbulu’nda Gündelik Yaşam.” 26 Haziran 2020. Meşher Podcast adlı podcast içinde. Hazırlayan Karoly Aliotti, Şeyda Çetin ve Ebru Esra Sat1c1. https://open.spotify.com/episode/2vhhLFbAhBaBDsLfRpe43R?si=BxEo0ZrxSp-16SFJiGI5Dg.

Üre, P1nar. "Byzantine Heritage, Archaeology, and Politics between Russia and the Ottoman Empire: Russian Archaeological Institute in Constantinople (1894-1914).” Doktora Tezi, The London School of Economics and Political Science, 2014. 
